\title{
ANGER AND GUILT IN TREATMENT FOR CHRONIC POSTTRAUMATIC STRESS DISORDER
}

by

\section{ERIN GEORGIANA CLIFTON}

Submitted in partial fulfillment of the requirements

for the degree of Master of Arts

Master's Advisor: Dr. Norah C. Feeny

Department of Psychological Sciences

CASE WESTERN RESERVE UNIVERSITY

January, 2013 


\section{CASE WESTERN RESERVE UNIVERSITY \\ SCHOOL OF GRADUATE STUDIES}

We hereby approve the thesis/dissertation of

( UQ* HRU IDQD\&QITRQ

candidate for the

0 DMMIRIIS UW___ degree * .

(signed)__ 1 RUK) HQ आ3K

(chair of the committee)

-DP HN2 YHKRQHU3K

- XOH( [

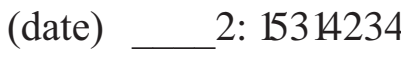

*We also certify that written approval has been obtained for any proprietary material contained therein. 


\section{Table of Contents}

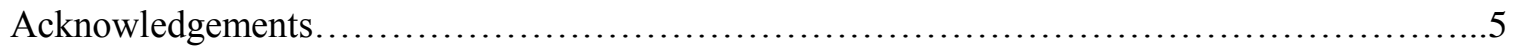

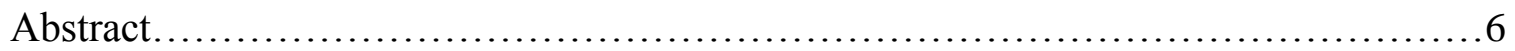

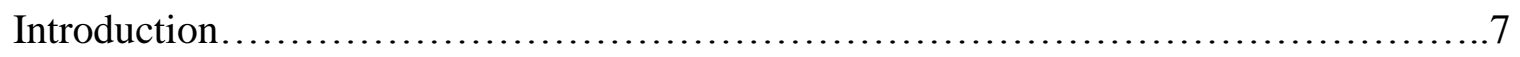

Understanding Baseline Psychopathology.....................................

Anger..................................................................

Guilt............................................................... 14

Guilt and Anger.................................................. 17

Comorbid Depression.................................................. 19

Understanding the Relationship between Emotional Engagement and Anger and Guilt..20

Understanding the Relationship between Treatment Outcome and Anger and Guilt.....22

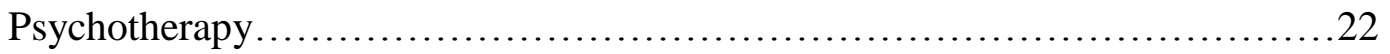

Pharmacotherapy.................................................... 25

Understanding the Relationship between Emotional Engagement and Treatment

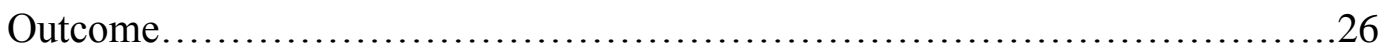

Study Aims and Hypotheses..................................................27

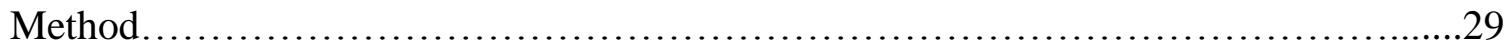

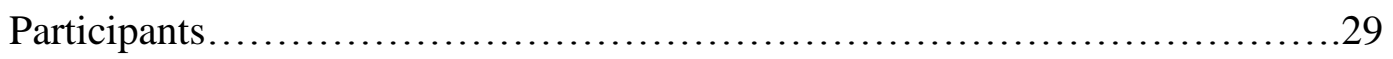

Measures............................................................... 30

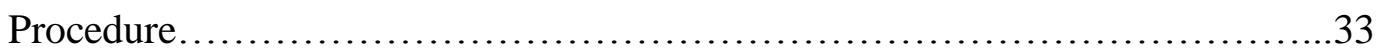

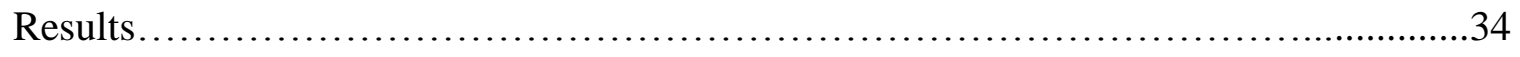

Discussion..............................................................43

Limitations and Future Directions.......................................... 54

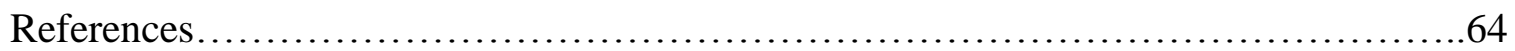


Figures

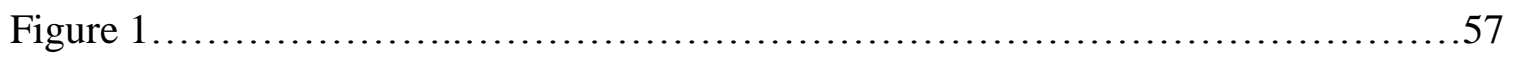




\section{Tables}

Table 1. Means and Standard Deviations of PTSD Symptoms, Anger Symptoms, Guilt Symptoms, and Depression Symptoms at Pre- and Posttreatment........................58

Table 2. Correlations among PTSD, Anger, Guilt, and Depression Measures.............59

Table 3. Regression Coefficients and Bootstrapped Point Estimates Examining Depression as a Mediator between PTSD Symptoms and Guilt at Baseline.

Table 4. Correlations among Anger, Guilt, and Emotional Engagement Measures.......61

Table 5. Regression Analyses Predicting Initial and Mean Emotional Engagement from

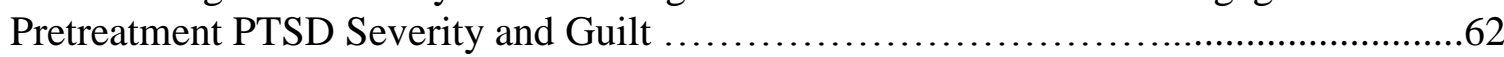

Table 6. Regression Analyses Predicting Treatment Outcome from Pretreatment Anger and Guilt when Controlling for Pretreatment PTSD Severity........................63 


\section{Acknowledgements}

Preparation of this manuscript was supported by grants to Drs. Zoellner and Feeny from the National Institute of Mental Health (R01 MH066347, R01 MH066348). The investigative team on the grants included: Peter Roy-Byrne, MD, Matig Mavissakalian, MD, Jason Doctor, Ph.D., Joshua McDavid, MD, and Nora McNamara, MD. I also acknowledge the support of The William T. Dahms, M.D. Clinical Research Unit, funded under the Cleveland Clinical and Translational Science Award (UL1 RR024989). Thank you to Norah Feeny, Ph.D., for serving as the chair of my Master's committee and her help and feedback on this project. Thank you to Julie Exline, Ph.D. and James Overholser, Ph.D. for serving as members of my Master's committee. 
Anger and Guilt in Treatment for Chronic Posttraumatic Stress Disorder

\author{
Abstract \\ by

\section{ERIN GEORGIANA CLIFTON}

Anger and guilt are associated with PTSD and depression (e.g., Novaco \& Chemtob, 2002; Henning \& Freuh, 1997). Yet, little work has investigated how anger, guilt, PTSD and depression relate in baseline psychopathology, treatment engagement, and outcome. The present study utilized baseline, in-session, and posttreatment data from two hundred trauma survivors with PTSD. The first aim examined the association between PTSD and anger and guilt at baseline and found depression to mediate the relationship between specific PTSD symptoms and guilt. The second aim investigated whether anger and guilt were negatively correlated with engagement. Lastly, aim three examined anger and guilt as predictors of worse treatment outcome and engagement as a mediator of treatment outcome. Results indicated that anger and guilt did not hinder emotional engagement and did not impede effective PTSD treatment. Anger and guilt decreased as a result of PTSD treatment implying tolerability and broad applicability of prolonged exposure. 
Anger and Guilt in Treatment for Chronic Posttraumatic Stress Disorder

Posttraumatic stress disorder (PTSD) is a prevalent, debilitating disorder that does not tend to remit without treatment (Kessler, Sonnega, Bromet, Hughes, \& Nelson, 1995; Rothbaum, Foa, Riggs, Murdock, \& Walsh, 1992). Exposure to traumatic events is common within our society (e.g., Kessler et al., 1995; Resnick, Kilpatrick, Dansky, Saunders, \& Best, 1993) and a substantial minority of trauma survivors go on to develop PTSD (Kessler et al., 1995). Among those who suffer from PTSD, co-occurring depression, substance abuse, and other mental and physical health concerns are common (Breslau, Davis, Andreski, \& Peterson, 1991; Keane \& Kalopek, 1997; Kessler et al., 1995; Davidson, Hughes, Blazer, \& George, 1991; Schnurr \& Green, 2004). Moreover, feelings of anger and guilt are significantly increased after traumatic events and positively associated with both PTSD and depression (e.g., Jakupcak et al., 2007; Novaco \& Chemtob, 2002; Henning \& Frueh, 1997; Kubany et al., 1995; Chemtob, Hamada, Roitblat, \& Muraka, 1994; Riggs et al., 1992). These negative emotions have been shown to contribute to persistence of PTSD and depression symptoms posttrauma (Kubany at al., 1996; Foa et al., 1995). Despite efficacious psychological and pharmacological treatment options for PTSD (e.g., Foa, Keane, Friedman, \& Cohen, 2008), several studies have shown anger and guilt to negatively affect treatment outcome (e.g. Taylor et al., 2001; Ehlers et al., 1998). As not all PTSD clients benefit from the current treatments and drop-out rates remain significant (e.g. Foa et al. 1999; Brady et al., 2000), having a better understanding of the relationship between anger, guilt and PTSD symptomology might help to better predict response to treatment. These considerations highlight the need for a better understanding of how anger and guilt contribute to persistence of PTSD 
and depression symptoms and whether these negative emotions function to affect PTSD severity.

This study built upon research investigating the relationship between anger, guilt, PTSD, and depression severity in individuals with chronic PTSD. Previous research has looked at anger and guilt in separate studies as predictors of PTSD severity (Owens, Steger, Whitesell, \& Herrera, 2009; Owens, Chard, \& Cox, 2008; Street et al., 2005; Forbes et al, 2003; Feeny Zoellner, \& Foa, 2000; Henning \& Frueh, 1997). However, few studies have examined anger and guilt conjointly. Similarly, few studies have investigated anger and guilt in relation to treatment for PTSD (Cahill et al., 2003; Stapleton, Taylor, \& Asmundson, 2006). Previous research has shown that both anger and guilt may exacerbate PTSD symptoms (Chemtob et al., 1997; Kubany \& Watson, 2003) and both were associated with intense distress and emotional and interpersonal difficulties (Baumeister, Stillwell, \& Heatherton, 1994; Jakupcak et al., 2007). Given the prevalence and impact of problems with both of these emotions in trauma-exposed individuals, it is important to investigate their potential commonalities further. In order to understand the complex relationship between anger and guilt and PTSD symptoms, the present study examined trauma-related psychopathology at baseline, during the first imaginal exposure as part of the third treatment session, and after treatment for chronic PTSD. The following sections will outline relevant background information for anger and guilt and their relation with PTSD symptomatology as well as discuss areas of the PTSD treatment process that may be affected by anger and guilt.

\section{Understanding Baseline Psychopathology}


PTSD is an anxiety disorder that develops in response to a traumatic event that involved actual or threatened death or serious injury with a reaction to this event of intense fear, helplessness, or horror (American Psychological Association, 2000). The three clusters of symptoms that comprise PTSD are re-experiencing, avoidance, and hyperarousal (APA, 2000). Despite the current Diagnostic and Statistical Manual of Mental Disorder's (DSM) three symptom clusters, factor analyses generally support four clusters. Indeed, Simms, Watson, and Doebbeling (2002) conducted confirmatory factor analyses to compare 6 empirically supported structural models of PTSD symptoms and the symptom structural model that provided the best fit to the data consisted of the following four factors: intrusions, avoidance, hyperarousal (consisting of two of the DSM-IV hyperarousal symptoms: hypervigilance and exaggerated startle response), and dysphoria (consisting of the DSM-IV emotional numbing symptoms and three of the DSM-IV hyperarousal symptoms: sleep disturbance, irritability, and impaired concentration). Each of these symptom clusters is distinct and affects different areas of psychological functioning. Little work has investigated the relationship between anger, guilt, PTSD and depression symptoms at the onset of treatment and as such, each cluster may be differentially related to anger and guilt.

In order to best understand the baseline relationship between anger and guilt and PTSD and depression symptoms, it is crucial to explore each construct on its own and in conjunction with one another.

Anger. Anger is defined by the experience and expression of hostile or furious feelings either expressed or withheld (Spielberger et al., 1985). Anger is a common symptom in individuals with PTSD resulting from a variety of traumatic events, 
including combat (e.g. Chemtob et al., 1994; Rosen et al., 2001), physical or sexual assault (e.g. Riggs et al., 1992; Feeny et al., 2000), terrorist attacks (Evans, Giosan, Patt, Spielman, \& Difede, 2006) and motor vehicle accidents (Mayou, Ehlers, \& Bryant, 2002). Indeed, the DSM-IV (APA, 2000) lists irritability and outbursts of anger as one of the hyperarousal symptoms of PTSD. However, even after removing items measuring anger in PTSD scales, the correlation between anger and PTSD does not decrease (Novaco \& Chemtob, 2002). Therefore, anger may be an important factor in PTSD symptomology not just an additional symptom of the disorder.

Evidence suggests that anger plays a prominent role in both mental and physical health symptoms following trauma. Indeed, increased anger has been linked to negative physical health symptoms (Krantz et al., 2006; Ouimette, Cronkite, Prins, \& Moos, 2004), adverse social/occupational functioning (Evans et al., 2006), and increased interpersonal violence (Jakupcak \& Tull, 2005; Swan, Gambone, Fields, Sullivan, \& Snow, 2005). Anger has also been associated with an increase in substance abuse (DeMoja \& Spielberger, 1997). Because anger has been associated with poor outcomes and comorbid difficulties, Monson and Friedman (2006) suggested that a diagnosis of PTSD should include specifiers such as "prominent anger" in order to better distinguish those individuals in whom anger is a major problem. Further, McHugh and colleagues (2011) recently argued for a focus on the capacity to imagine visual mental phenomena, like intrusive images, as crucial to the conceptualization and maintenance of anger in PTSD. In fact, they proposed investigating anger in PTSD as a distinct entity from other forms of anger (McHugh et al., 2011). 
Current models conceptualize anger as a multidimensional construct such that the severity of anger and way it is expressed can vary within the individual. For example, anger difficulties may be expressed in a tendency to suppress angry feelings (anger in), in a tendency to express anger outwardly towards other individuals or objects through physically or verbally aggressive behavior (anger out), or an inability to diminish angry feelings (anger control; Spielberger et al., 1985). Furthermore, anger can be experienced in a current state of angry feelings (state anger) or over time and in response to a variety of situations (trait anger; Spielberger, 1988).

Given that anger can be expressed in a number of different ways, previous research has explored whether certain manifestations of anger are more strongly associated with PTSD than others. In a recent meta-analysis of the strength of the relationship between anger and PTSD, Orth and Wieland (2006) found large effects for anger-in, and anger control suggesting that individuals with PTSD may struggle with inhibiting their anger response and disclosing their anger (anger-in). The authors suggested it is possible that strong posttraumatic stress reactions reduce the ability of the individual to control anger by decreasing mental resources (anger control). In addition, a recent longitudinal study by Meffert and colleagues (2008) found that greater trait anger during training predicted greater PTSD symptoms at one year among police officers. Notably, the authors found PTSD to be associated with an increase in state anger. In a recent meta-analytic review of the specificity of anger in PTSD, Olatunji, Ciesielki, and Tolin (2010) found that the specific association between anger and PTSD varied depending on the anger domain assessed, such that difficulties with anger control, angerin and anger-out were characteristic of individuals with PTSD verses other non-PTSD 
anxiety disorders. Thus, problems with anger can span different expressions as well as an individual's ability to control their anger which makes it more difficult to determine how anger may contribute to PTSD severity.

There are several competing theoretical conceptualizations of anger in relation to PTSD that go beyond simply defining how angry feelings are manifested. Cognitive models of PTSD suggest that PTSD severity is correlated with rumination about the trauma and its consequences. Ehlers and Clark (2000) proposed that anger arises from excessively negative appraisals of the trauma which in turn leads to maladaptive behavioral strategies to control threat and symptoms, one such strategy being avoidance, another being rumination. Indeed, in a study of civilian trauma survivors with and without PTSD, results indicated that catastrophic appraisals about oneself and time since trauma were the only significant predictors of anger expression (Whiting \& Bryant, 2007).

Another possible theoretical explanation for the relationship between PTSD and anger comes from Chemtob and colleagues (1997) who hypothesized that individuals with PTSD are significantly more sensitive to perceiving situations as threatening. This "survival mode" theory suggests that individuals with PTSD have a lowered threshold for threat perception which activates a biologically predisposed reaction that can include anger as a fight response (Chemtob et al., 1997). Novaco and Chemtob (2002) proposed that the engagement of anger in PTSD involves hostile appraisal, heightened arousal, and antagonistic behavior as survival mode responding in contextually inappropriate situations, and as such it is a dysregulation in response to trauma-related triggers. 
Anger as a survival mode in PTSD is related to work by emotions researcher, Peter Lang, in which perceiving and responding to a fear-inducing stimulus involves many complex systems within the brain and body (Lang, Davis, Ouml, \& hman, 2000). Broadly, an unpleasant emotion, such as fear, activates a specific circuit within the brain which in turn mediates autonomic (e.g. heart racing, palms sweating) and somatic changes (e.g. heightened startle reaction) within the body that prime a human for a defensive reaction (Lang et al., 2000). In addition, Lang discussed fear states in terms of two broad classes of outputs: defensive immobility, which is characterized by a state of high sensitivity for reaction, or defensive action, which is a direct response to danger. Responding to fear actively or defensively, or a combination of the two, depends on a number of factors, one being a prior memory of the danger. Our brain forms memories of dangerous situations we have encountered in the past which the brain will access in later fear states. "The property of an emotion memory network that differentiates it from other knowledge structures is that the emotion network has a strong connection to this primitive motivational circuitry," (Lang et al., 2000). Through this process, the fear circuit has promoted survival within our species and continues to do so. Thus, in survival mode theory, when an individual with PTSD perceives a threat, they may be more likely to activate an anger response as a defense.

An additional conceptualization of anger comes from Riggs et al. (1992) who hypothesized that individuals with PTSD are motivated to avoid feelings of fear and anxiety arising from trauma-related triggers and thoughts and that anger serves as a distractor from fear-eliciting trauma memories. Fear avoidance suggests that individuals with PTSD avoid trauma-based fear emotions that are elicited by intrusive trauma-related 
thoughts and that anger is a preferred emotional state to fear (Foa et al., 1995). As such, anger has been found to have a negative impact on the efficacy of exposure therapy by impeding an individual's ability to engage with their trauma memories (Foa et al., 1995). This theory is consistent with results from a prospective study of female crime victims of both sexual and nonsexual assault, in which Feeny, Zoellner, and Foa (2000) found that anger expression at four weeks post trauma predicted PTSD severity at three months post trauma. The authors theorized that anger may be a method of avoiding trauma-related emotions associated with PTSD severity.

In sum, research findings suggest that anger is not only just another potential symptom of PTSD; anger can increase and complicate PTSD severity (e.g. Meffert et al., 2008). There are differing theoretical explanations for relationship between anger and PTSD, however, all of them point to anger as a coping mechanism for perhaps more difficult fear-related emotions. The difficulties associated with increased anger emphasize the importance of examining anger in the context of baseline severity of PTSD in order to provide a foundation for further investigation of anger throughout the treatment process and in comparison to guilt.

Guilt. Guilt is defined as an unpleasant feeling with an accompanying belief (or beliefs) that one should have thought, felt, or acted differently (Kubany \& Manke, 1995). In terms of PTSD, guilt is conceptualized as a multidimensional construct consisting of five factors that are hypothesized to be determinants of the magnitude of guilt an individual will experience after exposure to a traumatic event (Kubany et al., 1995). These factors consist of (1) distress about a negative outcome and four inter-related belief's (also deemed cognitions) about one's role in the event: (2) perceived 
responsibility for causing the event, (3) perceived insufficient justification for actions taken, (4) perceived violation of values, and (5) beliefs about foreseeability and preventability of the event (Kubany \& Watson, 2003; Kubany \& Manke, 1995). Thus, the level of guilt an individual experiences is posited to be a function of the presence and magnitude of the combination of these factors. Importantly, this is similar to the experience of anger in those negative appraisals of the trauma and its aftermath can lead to increased levels of both emotions.

Guilt is described as an associated feature of PTSD, such that individuals with PTSD may describe painful guilt feelings about surviving when others did not survive or about things they had to do to survive (APA, 2000). Although guilt is not explicitly listed as one of the necessary symptoms for a diagnosis of PTSD, it has been shown to be a significant concern for individuals with PTSD resulting from a variety of traumatic events, including combat (Owens et al., 2009; Kubany, 1994), domestic violence (Street, et al., 2005), and sexual assault (Kubany et al., 1996). Furthermore, guilt has been linked to thoughts of suicide (Hendin \& Haas, 1991) and is highly correlated with depression (e.g. Marx et al., 2010). In fact, in a large multi-cite study of Vietnam veterans, combatrelated guilt completely mediated the association between participation in violence and both PTSD and MDD (Marx et al, 2010).

Guilt is often included in prominent theories of PTSD and includes both a cognitive and an affective component. It has been established that beliefs about one's role in trauma are important factors in posttrauma adjustment such that guilty cognitions and feelings following trauma are significantly correlated with severity of psychopathology (Kubany et al., 1995). Kubany and Manke (1995) theorized that PTSD 
is maintained by guilt through a cyclic pattern. They suggested that guilt-related cognitions often accompany traumatic memories and these guilty thoughts also produce a negative emotional response, such as distress, guilt, and anger, within the individual. Through this type of conditioning, traumatic memories trigger negative emotions, and the experience of the negative affect reinforces the aversive nature of the traumatic memory. In turn, this negative cycle tends to increase avoidance of the traumatic memory which reduces the likelihood of improvement through extinction and explains why these painful thoughts do not get better with time.

Compared to the relative breadth of empirical research on anger and PTSD, there is less research in the area of guilt as related to PTSD symptomology. This might be partly owed to the challenge in defining guilt as it often overlaps with definitions of shame. Recently, theorists suggested that guilt differs from shame such that guilt is a private recognition of wrongdoing while shame involves a form of self- condemnation (Wilson, Drozdek, \& Turkovic, 2006). According to Tangney and colleagues (1996), there is evidence to indicate that shame may motivate avoidant behavior and a defensive anger while, in contrast, guilt has been associated with a tendency to accept responsibility and with a somewhat decreased tendency toward interpersonal anger and hostility. Indeed, in a study conceptualizing the relationship between shame, guilt, and anger arousal, the authors found that guilt was associated with a higher likelihood of constructive means of handling anger, whereas shame was associated with more maladaptive responses to anger (Tangney et al., 1996). However, trauma-related guilt has been associated with greater use of avoidant coping strategies and subsequent increased PTSD symptomology (Street et al., 2005). Further, trauma-related guilt has 
been strongly associated with depression and potentially worsening PTSD severity and treatment response (Kubany et al., 1995; Owens, Chard, \& Cox, 2008). Both guilt and shame are complex emotional responses when related to the experience of trauma, and they have been conceptualized in a variety of ways by different theorists over the years (Andrews, Brewin, Rose, \& Kirk, 2000; Kubany \& Manke, 1995; Opp \& Sampson, 1989; Seidler, 1997; Wilson, Drozdek, \& Turkovic, 2006). For the purposes of this study, guilt will be utilized as defined by Kubany and Manke (1995) as these authors have a long history of conceptualizing guilt as related to PTSD.

Guilt and Anger. In this study, we examined both anger and guilt for several reasons. Both anger and guilt may contribute to the onset and maintenance of PTSD (e.g. Kubany et al., 1996; Foa et al., 1995) as well as interfere with standard treatment of PTSD for some people (Foa et al., 1995; Taylor et al., 2001; Ehlers et al., 1998). They also share a common definition in that they are unpleasant feelings accompanied by a belief that one (guilt) or someone else (anger) should have thought, felt, or acted differently (Weiner, Graham, \& Chandler, 1982). Guilt involves appraisals about self, whereas anger involves attributions about others (Ellsworth, 1994; Weiner et al., 1982). However, despite the similarities in their relationship to PTSD, few studies have examined anger and guilt within the same sample.

As evidenced in the previous literature review, anger and guilt are commonly experienced after traumatic events and can be associated with worse severity in the experience of PTSD (e.g. Taylor et al., 2001; Ehlers et al., 1998; Foa et al., 1995). This similar association to PTSD could be owed to anger and guilt being functionally similar. Both anger and guilt have been shown to arise from negative appraisals of a traumatic 
event which can lead to increased avoidance as a coping strategy (Street, Gibson \& Holohan, 2005; Ehlers \& Clark, 2000; Henning \& Frueh, 1997). For example, Dunmore, Clark \& Ehlers (1999) hypothesized that negative appraisals of trauma and its sequelae, such as guilt, dysfunctional strategies (such as avoidance) and global beliefs impacted by trauma are all associated with onset and maintenance of PTSD symptoms in sexual assault survivors.

Avoidance is at the crux of PTSD symptomology and includes "anhedonia, emotional detachment, restricted range of affect, and avoidance of reminders of the trauma" (APA, 2000, p. 468). Furthermore, avoidance as a method of coping is associated with worse PTSD symptomology (Gibson \& Leitenberg, 2001; Clohessy \& Ehlers, 1999; Bryant \& Harvey, 1995). Kubany and Manke (1995) suggested that traumatic events are often accompanied by guilt-related cognitions that produce a negative emotional response. Memories of the trauma may trigger this negative emotional response which continues the aversive nature of the trauma memory. Moreover, this cycle of negative emotion may intensify avoidance as a coping strategy, thereby reducing the likelihood of recovery. It is possible that anger fits into this equation such that if guilt related cognitions serve as posttraumatic intrusions, then consistent with the conceptualization of anger as a fear avoidance strategy, anger may serve as a distraction from the fear-inducing cognitions. Indeed, some of the more prominent theories about this relationship suggest that anger interferes with emotional processing of the trauma (Foa et al., 1995; Paunovic, 1998) and that guilt, along with feelings of shame, may maintain PTSD. 
Comorbid Depression. Additionally, because depression is highly comorbid with PTSD (Breslau, et al., 1991) and also related to guilt and anger, it could be a potential mediator between specific PTSD symptom clusters and anger or guilt. Individuals with comorbid PTSD and depression tend to show more severe symptoms than either disorder alone (Blanchard, Buckley, Hickling, \& Taylor, 1998; Post, Zoellner, Youngstrom, \& Feeny, in press). For example, sexual assault survivors with comorbid depression appear to have poorer outcome following treatment than those with PTSD alone (Resnick, Nishith, Weaver, Astin, \& Feuer, 2002). In addition, in a study of 134 Vietnam veterans with combat-related PTSD, Forbes et al. (2003) found depression, along with anger and alcohol, to be a significant predictor of symptom change after treatment PTSD.

Dohrenwend et al. (2006) found that more depressed veterans often report higher levels of PTSD. In a study examining combat-related guilt and PTSD and depression in male Vietnam War veterans, Marx et al. (2010) found that guilt was a mediator between exposure to combat-related abusive violence and subsequent PTSD and depression. The close relationship between guilt, depression and PTSD highlights the importance of investigating these phenomena in the context of treatment outcome research. Furthermore, the avoidance cluster of symptoms is of particular interest given the significant relationship between avoidant coping and anger and guilt.

In summary, although significant relationships have been established between anger, guilt, and PTSD severity, little work has investigated the relationship between anger, guilt, PTSD and depression symptoms at the onset of treatment. As a result of the paucity of literature involving a combined examination of anger and guilt, it is unknown whether these negative emotions are uniquely related to certain PTSD symptom clusters 
at baseline. Given the positive relationship between anger and guilt and increased avoidance (Street et al., 2005; Ehlers \& Clark, 2000; Henning \&Frueh, 1997), anger and guilt may have a relationship to the avoidance cluster of PTSD symptoms. The current study examined anger and guilt at baseline in the attempts to better understand these negative emotions before treatment has altered their expression.

\section{Understanding the Relationship between Emotional Engagement and Anger and Guilt}

Beyond examining anger and guilt's relationship to PTSD symptomology prior to treatment, little is known about how they affect the treatment process. Current models of PTSD indicate that emotional engagement is crucial for successful treatment of PTSD (Foa \& Kozak, 1986). Emotional engagement occurs when an individual activates and engages with fear-related emotions during treatment, which is not an easy process for many individuals as these emotions are often painful and avoided as part of PTSD. An effective intervention for the treatment of chronic PTSD is prolonged exposure therapy (PE; Foa et al., 1999; 2005; IOM, 2006). PE is generally well tolerated (Foa, Franklin, \& Moser, 2002) and requires emotional engagement with once avoided emotions. An essential part of PE therapy is repeated imaginal exposure to trauma memories which involves actively remembering and discussing their traumatic memories. According to Foa and Kozak (1986) emotional processing of the trauma memory involves accessing the fear structure, which can be viewed as cognitive representations of the stimuli characteristic of the fear situation, the individual's responses in it, and aspects of its meaning for the individual, and then incorporating new information into the existing structure in order to decrease emotional response to the memory and trauma-related 
triggers of PTSD symptoms. If this therapy process is successful, habituation and recovery from PTSD symptoms will occur (Foa \& Kozak, 1986).

One of the few empirical studies on the influence of emotional engagement on exposure therapy for PTSD comes from Jaycox, Foa, and Morral (1998). In a study of thirty-seven female assault victims, the authors found three patterns of emotional response to imaginal exposure therapy: high initial emotional engagement and a gradual decrease in anxiety over sessions, high initial emotional engagement and low habituation to anxiety over sessions, and moderate initial engagement and low habituation. Although clients in all three groups benefitted from treatment, individuals with high emotional engagement followed by habituation of anxiety over sessions were eight times more likely to meet their stringent criteria for good end-state functioning. These findings suggest that emotional engagement is crucial for the efficacious treatment of PTSD while highlighting the importance of examining factors, such as anger and/or guilt, that might impede emotional engagement.

Anger and guilt have been conceptualized to reflect emotional disengagement from trauma memories, which has been thought to interfere with successful recovery (Foa \& Rothbaum, 1998). It is hypothesized that activation of an anger structure might prevent activation of the fear structure thus inhibiting recovery from symptoms (Cahill et al., 2003). Theory suggests that anger impedes emotional processing of the trauma memory such that trauma-related triggers will activate similar elements in both fear and anger structures (Riggs et al., 1992). Then, individuals may learn to activate the anger structure in order to avoid anxiety that is associated with fear. In a study of 104 female sexual assault victims, Feeny et al. (2000) found that anger expression at 4 weeks post- 
assault was predictive of later PTSD severity. The authors theorized that initial anger may hinder fear activation and subsequent PTSD severity due to a lack of emotional processing. Thus, anger is viewed as a method of avoiding engagement with traumarelated emotions (Feeny et al., 2000).

Avoidance can affect one's ability to be emotionally engaged with trauma memories. Given anger and guilt's relationship to avoidance, it is possible that increased anger and/or guilt might decrease a person's ability to engage in and be successful in treatment for chronic PTSD. Most studies of anger and guilt have examined them as risk factors for worsening of PTSD symptoms, not how they may affect the therapy process by means of emotional engagement. There is limited data on the effect of anger and guilt on engagement in treatment. Moreover, the literature on guilt's potential effect on emotional engagement is especially lacking, thereby making the study of emotional engagement in an empirically-supported PTSD treatment a unique contribution to the literature.

\section{Understanding the Relationship between Treatment Outcome and Anger and Guilt}

Psychotherapy. In the context of treatment studies, pretreatment anger has been related to poor outcome (Foa et al., 1995; Forbes et al, 2003; Taylor et al., 2001). For example, in a study of twelve female assault victims with PTSD who received imaginal exposure therapy, Foa at al. (1995) found that the degree of anger experienced during an exposure task predicted worse treatment outcome. Results indicated that clients who reported more anger at pretreatment tended to display less fear expression, a measure of fear activation, during the exposure session and benefitted less from treatment then their less angry peers (Foa et al., 1995). As another example, in a study of Australian Vietnam 
veterans with PTSD, anger was found to be the most significant predictor of symptom change after treatment for PTSD (Forbes et al., 2003). The authors found that individuals with high levels of anger at intake fared worse at 9-month follow up (Forbes et al., 2003).

Moreover, Rizvi, Vogt, and Resick (2009) found that women with higher anger at pretreatment were more likely to drop out of PE therapy for PTSD. Longitudinal studies show that high levels of anger (Ehlers, Mayou, \& Bryant, 1998) and more specifically anger with others (Andrews et al., 2000) predict a slower recovery from PTSD. Another study found that anger correlated negatively with PTSD treatment outcome in a group of combat veterans attending PTSD treatment (Forbes et al., 2008). Furthermore, they found that fear of one's anger was more predictive than general anger suggesting that veterans who are afraid of their inability to control their angry responses may be more hesitant to explore trauma memories than veterans who do not fear their anger (Forbes et al., 2008). The authors suggested that this may be because veterans who are afraid of their anger are fearful that accessing the trauma memory may trigger an aggressive and harmful response. All of these studies show that high levels of anger are related to poor outcome. Perhaps anger is another means in which individuals with PTSD can regulate distress when emotional pain is triggered during psychotherapy.

However, other studies have found no significant association between anger and treatment outcome (e.g. Cahill et al., 2003; Taylor et al., 2003). For instance, in a study examining the effects of cognitive behavioral therapies (CBT) for PTSD on anger, anger did not significantly reduce the efficacy of CBT and, in fact, treatment for PTSD reduced anger (Cahill et al., 2003). Indeed, the authors found that groups with high and low anger at pretreatment did not differ in anger at posttreatment (Cahill et al., 2003). These 
findings are consistent with work by Chemtob and colleagues (1997) in which treatment for anger in veterans with PTSD resulted in decreased anger and PTSD symptoms. In a study examining cognitive and affective predictors of treatment outcome in psychotherapies for PTSD, no significant effects of anger on treatment efficacy were found (Rizvi, Vogt, \& Resick, 2009). van Minnen, Arntz \& Keijsers (2002) investigated predictors of treatment outcome in two samples of PTSD patients treated using PE and found that neither feelings of anger nor guilt were related to treatment outcome.

Previous findings on guilt's effect on treatment outcome are mixed as well. In terms of guilt's relation to treatment outcome, Rizvi, Vogt \& Resick (2009) found that individuals with higher depression and global guilt at pretreatment demonstrated a greater reduction in PTSD symptoms over time. Contrastingly, Ehlers et al. (1998) studied transcripts of exposure treatment in 10 women with good treatment outcome and 10 women with poor treatment outcome and found that poor outcome is related to mental defeat and alienation which they suggest is due to feelings of guilt and shame. Furthermore, Paunovic (1998) also suggested that guilt may interfere with PTSD treatment indicating that guilt and shame lead to intrusive memories and avoidance of the trauma, thereby maintaining PTSD symptoms.

Guilt and depression have been identified as significant predictors of PTSD severity (Owens et al., 2009), which could affect subsequent treatment. Moreover, research suggests that guilt may interfere with PTSD treatment, such that in a study exploring cognitive differences between those individuals who respond well to exposure therapy verses those who do not, mental defeat and alienation, which the authors suggest are correlates of guilt, were related to inferior outcome (Ehlers et al., 1998). Anger is also 
related to poor treatment outcome in some studies (Foa, et al., 1995; Forbes et al., 2003; Taylor et al., 2001). However, it is still unknown how anger and guilt may affect treatment response. Because the existing literature on anger and guilt as predictors of treatment outcome are mixed, it is necessary to further investigate their effect on treatment outcome.

Pharmacotherapy. Another empirically-supported intervention for PTSD is sertraline (SERT), a selective serotonin reuptake inhibitor (SSRI; Brady et al, 2000; Davidson et al., 2001). Sertraline has been approved by the Food and Drug Administration as a treatment for PTSD (U.S. Department of Food and Drug Administration, Department of Health and Human Services) and has demonstrated greater symptom reduction on all symptom clusters than placebo in randomized controlled trials (Brady et al., 2000; Davidson et al., 2001). It is possible that sertraline improves regulation of emotions and memory modulation allowing the individual to access previously overwhelming and unprocessed traumatic memories (Davidson et al., 2002).

While sertraline is an efficacious treatment for PTSD, dropout rates among those receiving pharmacological treatment for PTSD are significant and higher than that of psychotherapy PTSD treatment (Brady et al., 2000). In a randomized controlled trial comparing sertraline to placebo, the dropout rate was approximately $30 \%$ for those receiving sertraline (Brady et al., 2000). Furthermore, despite the efficacy of sertraline for the treatment of PTSD, not everyone benefits from this treatment, with estimates of approximately 50\% classified as non-responders at the end of treatment (Brady et al., 2000). Non-response could be result of a number of reasons besides a physical adverse 
reaction to the medication, such as not adhering to protocol, withdrawal of consent, or for an unknown reason (Brady et al., 2000). Thus, it is important to consider other sources of negative reaction to treatment, such as the potential effects of anger or guilt on medication adherence.

There are only a few studies that have examined the effects of sertraline on anger as related to PTSD symptomology. In a study examining the effects of sertraline on the individual symptoms of PTSD, Davidson et al. (2002) found significant treatment effects for anger present by week 1 which they presumed partly explained the subsequent observed effects of sertraline on other PTSD symptoms. Furthermore, Davidson, Landerman, and Clary (2004) found that an increase in anger of 30\% at one-week best predicted the likelihood of not responding to treatment in both drug and placebo group. Interestingly, there are no studies to date looking at improvement of feelings of guilt following medication treatment for PTSD. Thus, it remains to be determined if and how anger and guilt affect treatment for chronic PTSD, especially if it affects medication adherence or change in symptoms after pharmacological treatment. By examining their possible effect on pharmacological treatment outcome for PTSD, it might be possible to better promote treatment adherence.

\section{Understanding the Relationship between Emotional Engagement and Treatment Outcome}

One way in which anger and guilt could impact treatment outcome is via impeded emotional engagement. Exposure-based therapies for anxiety disorders are based on the idea that the relevant fear network must be activated and corrective information introduced in the context of affective arousal, which calls for the individual to be 
emotionally engaged during therapy (Foa, Huppert, \& Cahill, 2006). Indeed, many studies of anxiety disorders in general lend support to the idea that fear activation during exposure therapy is positively related to treatment outcome (e.g. Foa et al., 1995). The process of fear activation requires the individual to be emotionally engaged with their trauma memory within the therapy session (Jaycox, Foa and Morral, 1998).

Subsequently, emotional engagement in therapy predicts greater improvement in treatment (Jaycox, Foa and Morral, 1998).

The relationship between anger and guilt and PTSD treatment outcome is still unclear as anger and guilt have been shown interfere with PTSD treatment in some studies (e.g. Taylor et al., 2001; Ehlers \& Clark et al., 1998), but not others (e.g. Cahill, Rauch, Hembree, \& Foa, 2006). However, Jaycox, Foa \& Morrel (1998) found emotional engagement during exposure treatment to be essential to treatment success, thus, lack of emotional engagement may mediate the relationship between anger and guilt and poor treatment outcome. Given that emotional disengagement may occur as a result of avoidance used as a coping strategy when facing trauma-related triggers, such as recounting a trauma memory as part of imaginal exposure, and that anger and guilt are also related to avoidance, it is possible that there is a significant relationship between all of these variables.

Thus, in order to elucidate whether disengagement from imaginal exposure early in the therapy process is a method in which anger and guilt affect treatment outcome, it is essential to examine engagement as a mediator between initial levels of anger and guilt and treatment outcome.

\section{Study Aims and Hypotheses}


In order to provide a more nuanced understanding of how anger and guilt may influence PTSD and depression symptoms at the onset of treatment, during initial treatment sessions and after treatment for chronic PTSD, the present study's major aims were to examine among a sample of men and women with chronic PTSD (1) the relationship between PTSD symptom clusters and anger or guilt at baseline and whether depression mediated this relationship, with a particular focus on the avoidance cluster of symptoms (2) the association between anger and guilt and initial engagement in exposure therapy (3) as general predictors of worse treatment outcome and, in PE, whether engagement was a mediator of treatment outcome.

Aim 1 Hypothesis. It was hypothesized that initial level of PTSD severity would be positively correlated with baseline levels of anger and guilt and depression would most strongly mediate the relationship between the avoidance cluster of symptoms and anger or guilt. This hypothesis wass based on prior research demonstrating a positive correlation between severity of anger and guilt and severity of PTSD symptoms (Henning \& Frueh, 1997; Riggs, et al., 1992) and research linking anger and guilt to increased avoidance (Street, et al., 2005; Ehlers \& Clark, 2000; Henning \&Frueh, 1997).

Aim 2 Hypothesis. Based on previous literature linking anger and guilt to increased avoidance (Street, et al., 2005; Ehlers \& Clark, 2000; Henning \& Frueh, 1997) and literature highlighting the role of avoidance in emotional disengagement (Foa \& Rothbaum, 1998), it was hypothesized that anger and guilt would be negatively correlated with emotional engagement in the initial session of exposure therapy.

Aim 3 Hypothesis. It was hypothesized that anger and guilt would be general predictors of worse treatment outcome. Additionally, given the relationship between 
emotional engagement in PTSD therapy and treatment outcome (Foa\&Kozak, 1986), it was hypothesized that emotional engagement would mediate the relationship between baseline level of anger or guilt and treatment outcome.

\section{Method}

\section{Participants}

The sample consisted of two hundred male $(24.5 \%, n=49)$ and female $(75.5 \%, n=$ 151) trauma survivors with a primary diagnosis of chronic PTSD who participated in a randomized, controlled trial examining choice of Prolonged Exposure therapy verses sertraline for the treatment of chronic PTSD. The mean age of the participants was 37.41 $(S D=11.30)$ years and $65 \%$ of the participants were Caucasian, with the remaining $35 \%$ identifying with a minority background. When reporting the traumatic event that bothered them the most, $31.0 \%$ described experiencing an adult sexual assault, $22.5 \%$ non-sexual assault, $24.0 \%$ childhood sexual assault, $6.5 \%$ death or violence to a loved one, $13.5 \%$ a serious accident and $2.5 \%$ combat. On average, it had been $11.97(S D=12.69)$ years since experiencing the trauma associated with their current PTSD diagnosis. In addition, of the 200 individuals that participated in the study, $75.5 \%$ endorsed current MDD upon intake into the study.

Participants were recruited through community referrals, fliers, and advertisements in two large metropolitan areas. Inclusion criteria were a primary DSM-IV diagnosis of current, chronic PTSD and the ages 18 through 65 years. Exclusion criteria included a current diagnosis of schizophrenia or delusional disorder, medically unstable bipolar disorder, depression with psychotic features or severe enough to require immediate psychiatric treatment, alcohol or substance dependence within three months prior to 
assessment, or an ongoing intimate relationship with the perpetrator (in assault cases). Ineligible participants were offered appropriate referrals. Eligible participants were randomly assigned to either choice of treatment or no choice of treatment. Those who were given a choice were allowed to choose between ten weeks of pharmacotherapy, sertraline, or prolonged exposure therapy, while those who were not given a choice were randomly assigned to one of the two treatment options.

\section{Measures}

\section{PTSD Symptom Scale-Interview (PSS-I; Foa, Riggs, Dancu, \& Rothbaum,}

1993). Current PTSD diagnosis and severity was assessed using the PSS-I, a 17-item interview measure that uses DSM-IV symptom criteria. Each item is rated on a fourpoint Likert scale ranging from 0 to 3 based on frequency and/or severity, with higher levels indicating greater PTSD severity. PTSD diagnosis was attained if at least one reexperiencing, three avoidance, and two arousal items were endorsed. The PSS-I demonstrates good validity and reliability, including good convergent validity (sensitivity $=88 \%$; specificity $=96 \%$ ), an inter-rater reliability for PTSD diagnosis of $k=.91$, and an intraclass correlation for overall severity of $r=.97$ (Foa et al., 1993).

The PSSI was used to calculate the dysphoria, re-experiencing, avoidance, and hyperarousal symptom clusters proposed by Simms and colleagues (2002). The dysphoria symptom cluster consists of inability to recall aspects of trauma, loss of interest, detachment, restricted affect, sense of foreshortened future, sleep disturbance, irritability, and difficulty concentrating; the re-experiencing symptom cluster consists of intrusive thoughts of trauma, recurrent dreams of trauma, flashbacks, emotional reactivity to trauma cues, and physiological reactivity to trauma cues; the avoidance symptom 
cluster consists of avoiding thoughts of trauma and avoiding reminders of trauma; the hyperarousal symptom cluster consists of hypervigilance and exaggerated startle response. The items in each cluster were summed which accounted for the total score of each cluster.

Trauma-Related Guilt Inventory (TRGI; Kubany et al., 1996). The TRGI is a 32-item inventory that assesses guilt feelings and beliefs related to a traumatic event. The TRGI consists of three scales: the Global Guilt Scale (4 items), the Distress Scale (6 items), and the Guilt Cognitions scale (22 items) and three subscales (Hindsight Bias, Wrongdoing, and lack of Justification) that make up the cognitions. Each item is rated on a five-point Likert scale ranging from 1 (not at all true) to 5 (extremely true), with higher scores indicating higher guilt on the applicable scale. Kubany et al. (1996) reported internal-consistency estimated in a sample of battered women of .90 for the Global Guilt Scale and .86 for the Distress and Guilt Cognitions Scales. The Global Guilt Scale had a test-retest correlation of .86. Further, the TRGI was reportedly highly correlated with two measures of trait guilt and with measures of PTSD, depression, self-esteem, social anxiety and avoidance, and suicidal ideation (Kubany et al., 1996). The Global Guilt Scale was the only TRGI scale utilized in this study due to its centrality to the hypotheses.

State-Trait Anger Expression Inventory (STAXI; Spielberger, 1988). The STAXI is a 44-item inventory that assesses the experience, expression, and control of anger. The primary state anger scale, designed to assess one's intensity of anger at the time the instrument is completed, will be used in the present study as we were interested in assessing how an individual's current level of anger might affect engagement and 
outcome of therapy. The state scale consists of 10 items in which individuals assessed how they felt "right now." Each item is rated on a 4-point Likert scale ranging from 1 (not at all) to 4 (very much so). The STAXI scales have demonstrated good convergent validity with other measures of anger-hostility (Spielberger et al., 1985). In addition, the internal consistency of the State Anger and Trait Anger scales has been shown to be quite high $(\alpha=.93$ and .86, respectively; Spielberger, 1988). The construct validity of State Anger scores has shown to be reliable (Kamarck, Manuck, \& Jennings, 1990).

\section{Beck Depression Inventory (BDI; Beck, Ward, Mendelson, Mock, \&}

Erbaugh, 1961). The BDI is a widely-used, 21-item self-report questionnaire that is used to assess cognitive and vegetative symptoms of depression. Each item has a set of four answer choices rated from 0 to 3 , ranging in intensity about how the subject has been feeling in the past week. Item ratings are totaled to yield a total depression severity index with higher scores indicate higher levels of depressive symptoms. Test-retest reliability in psychiatric patients ranges from .46 to .86 with .65 test-retest reliability over a one-week period in depressed patients (Beck, Steer, \& Garbin, 1988). The BDI has been used in a number of previous studies examining depression as related to PTSD (e.g. Blanchard et al., 1998; Foa et al., 2005).

Emotional Engagement. Emotional engagement was measured using the subjective units of distress scale (SUDs; Wolpe \& Lazarus, 1966), where 100 represents the worst anxiety ever felt or could be imagined and 0 represents feeling completely calm and relaxed. During imaginal exposure sessions, the therapist elicited state ratings of distress (SUDs) from the participant every 5 minutes throughout the length of the exposure. The present study utilized initial, peak, and post distress ratings throughout the 
imaginal exposure session to measure how distressed, and thus emotionally engaged the participant was during the exposure session. In general, greater frequency, length and intensity of exposure are associated with higher SUDs ratings (Kazdin \& Wilcoxin, 1976). In addition, higher SUDs ratings are positively associated with measures of state anxiety (Kaplan, Smith, \& Coons, 1995) as well as physiological arousal, such as heart rate, peripheral vasoconstriction and digit temperature (Thayer, Papsdorf, Davis, \& Vallecorsa, 1984) suggesting good convergent validity. SUDs ratings have been used in previous studies to measure level of emotional engagement or fear activation (Foa et al., 1995, Jaycox, Foa, \& Morral, 1998).

\section{Procedure}

The data for this paper came from a NIH-funded treatment study for chronic PTSD. Initial eligibility was determined through a semi-structured phone screen, and potentially eligible participants were scheduled for an intake evaluation. After informed consent procedures, an independent evaluator conducted the intake evaluation consisting of structured interviews (PSS-I). If deemed eligible following the initial intake, participants returned for a randomization appointment in which their treatment condition was randomly assigned. Participants also completed a battery of self-report measures including measures assessing severity of PTSD (PSS-SR), depression (BDI), anger (STAXI), and guilt (TRGI). Following this visit, patients received 10 weekly sessions of psychotherapy, PE, or pharmacotherapy, SERT, for their chronic PTSD. During subsequent PE imaginal exposure sessions, participants gave self-report ratings of their distress (SUDs) every 5 minutes. Following treatment, participants completed a posttreatment evaluation that again included structured interviews (PSS-I) and self-report 
measures (BDI, STAXI, TRGI).

\section{Results}

Power and Preliminary Analyses. A priori, we determined medium effect sizes (Cohen's $d=.3$ or above) to be potentially clinically meaningful. Using the G-Power 3 software (Faul, Erdfelder, Lang, \& Buchner, 2007), given the number of variables and our sample size, we were well powered (.90 and above) to detect such effect sizes for each study aim.

Prior to regression analyses, all data will be screened using SPSS REGRESSION and SPSS FREQUENCIES for an evaluation of assumptions. A histogram of the residuals of each variable will be plotted against the normal curve to determine normality. Data that is greater than 3 standard deviations above or below the mean will be deleted from the data set.

Sample Characteristics. Means, standard deviations, and ranges at pre- and posttreatment for each of the measures are listed in Table 1. PTSD scores ranged from moderate to severe. Anger symptoms (STAXI) ranged from mild to severe with mean scores in the moderate range. Guilt symptoms (TRGI) ranged from absent to severe with mean scores in the moderate range. Similarly, depression (BDI) ranged from mild to severe with mean scores in the moderate range. Preliminary analyses were performed to ensure no violation of assumptions of normality, linearity, and homoscedasticity. There were no significant differences on measures of baseline PTSD, guilt, anger, or depression severity according to main demographic characteristics (i.e., gender, education, ethnicity, and trauma type).

\section{Aim 1: PTSD Severity and Anger and Guilt at Baseline}




\section{Is PTSD Severity Associated With Severity of Anger and/or Severity of Guilt}

at Baseline? In order to examine the relationships between PTSD severity and anger and guilt, zero order correlations between baseline PTSD symptoms (PSS-I), baseline state anger (STAXI), and baseline guilt (TRGI) were examined. Cohen (1988) suggests the following guidelines in interpreting the strength of the effect: small, $r=.10$ to .29 , medium, $r=.30$ to .49 , and large, $r=.50$ to 1.0. As shown in Table 2 , consistent with the hypothesis that PTSD severity would be related to guilt at baseline, there was a small positive correlation between pretreatment total PSS-I and TRGI scores, $r=.21, p<.01$, such that greater overall PTSD severity was related to higher levels of guilt at pretreatment. However, contrary to our hypothesis that PTSD severity would be related to anger at baseline, there was no significant association between baseline anger (STAXI) and total PTSD severity (PSS-I).

In order to examine the relationships between PTSD symptom clusters (intrusions, avoidance, hyperarousal, and dysphoria; Simms et al., 2002) and anger and guilt at baseline, again, zero order correlations were examined. As shown in Table 2, there was a small, positive correlation between the intrusions symptom cluster and TRGI scores, $\mathrm{r}=.21, p<.01$ and the dysphoria symptom cluster and TRGI scores, $r=.17, p<$ .01 . In addition, there was a trend level association between the avoidance cluster of symptoms and guilt, $r=.14, p<.053$. Contrary to the hypothesis that the avoidance cluster of symptoms, specifically, would be associated with anger and guilt, only the intrusions and dysphoria clusters were significantly related to guilt. None of the PTSD symptom clusters were significantly associated with anger. 


\section{Does Depression Mediate the Relationship between overall PTSD and anger}

or the Relationship between overall PTSD and guilt? To test the hypothesis that depression symptom severity (BDI) at baseline would mediate the relationship between PTSD symptom severity (PSS-I) ${ }^{1}$ and anger (STAXI) or guilt (TRGI), mediation analyses were conducted using a non-parametric bootstrapping approach (Preacher \& Hayes, $2004 ; 2008)$. This analytic approach is superior to the mediation analyses proposed by Baron and Kenny (1986) or the Sobel test (1982) because it (a) formally assesses whether the difference between the $\mathrm{c}$ and $\mathrm{c}$ ' paths is statistically significant but does not require a normal distribution of the cross product and (b) does not separately test the significance of the a and $\mathrm{b}$ paths without adjusting for the mathematical fact that as the a path becomes larger the b path becomes smaller and vice versa (Preacher \& Hayes, 2004, 2008).

Given that neither overall PTSD severity nor the PTSD symptom clusters were found to be significantly related to anger in our sample, we only examined whether the relationship between overall PTSD severity and guilt was mediated by depression. We used the SPSS mediation macros created by Preacher and Hayes (2008) to conduct these analyses. This method tests the statistical significance of the cross product of the relationship between the independent variable and the mediator (the a coefficient in Figure 1) and the relationship between the mediator and the dependent variable (the $b$ coefficient in Figure 1), which in finite data sets is generally equal to the difference between the direct effect (the c coefficient in Figure 1; the relationship between the

\footnotetext{
${ }^{1}$ We made the decision to use the PTSD Symptom Scale-Interview (PSS-I; Foa, Riggs, Dancu, \& Rothbaum, 1993) rather than a self-reported measure of PTSD severity, such as the PTSD Symptom Scale-Self Report (PSS-SR; Foa et al., 1993), as the interview measure is arguably a more accurate portrayal of PTSD symptoms and severity.
} 
independent variable and dependent variable) and indirect effects (the c' coefficient in Figure 1; the relationship between the independent variable and the dependent variable when controlling for the mediator), such that $\mathrm{a}^{*} \mathrm{~b}=\mathrm{c}-\mathrm{c}^{\prime}$. As a result, there is evidence of mediation when the $a^{*} b$ cross product is statistically significant. As shown in Table 3, the $95 \%$ confidence interval for the $\mathrm{a} * \mathrm{~b}$ coefficient did not contain zero. Thus, at $p<.05$, depression symptom severity (BDI) mediated the relationship between overall PTSD symptomology (PSS-I) and guilt (TRGI).

Does depression mediate the relationship between the avoidance cluster of PTSD symptoms and anger or guilt? As the correlation between the avoidance cluster of symptoms and guilt was approaching significance, we tested the hypothesis that depression symptom severity (BDI) would mediate the relationship between PTSD avoidance symptom severity (PSS-I) and guilt (TRGI), As shown in Table 3, depression severity at baseline (BDI) was not found to mediate the relationship between avoidance symptoms and guilt, however, this mediation relationship was approaching significance, $p=.0545$.

Does Depression mediate the relationship between the other PTSD subscales and anger and guilt? The final goal of the first aim was to examine whether depression would mediate the relationship between Simms et al's (2002) intrusions and dysphoria symptom clusters and anger and guilt, as these symptom clusters were found to be significantly correlated with anger and guilt, see Table 2. Again, we used Preacher and Hayes's (2008) mediation macro and conducted analyses to examine whether depression mediated the relationship between the intrusions and dysphoria PTSD symptom clusters and anger and guilt measures. Anger was excluded from the model as there was no 
significant association between anger and the PTSD symptom clusters. The intrusions and dysphoria symptom clusters were entered as the independent variables, depression scores were entered as the mediator and guilt was added as the dependent variable. As shown in Table 3 , the $95 \%$ confidence interval for the $a^{*} b$ coefficient did not contain zero. Thus, at $p<.05$, depression symptom severity mediated the relationship between guilt and the specific PTSD symptom clusters (intrusions and dysphoria).

\section{Aim 2: Anger, Guilt and Emotional Engagement}

\section{Are anger and/or guilt negatively correlated with emotional engagement in}

the first session of imaginal exposure? In order to examine the relationships between anger and guilt prior to treatment with emotional engagement at the initial session of imaginal exposure, zero order correlations between baseline anger (STAXI) and emotional engagement (SUDs) and between baseline guilt (TRGI) and emotional engagement (SUDs scores) were examined. We predicted that anger and guilt would be negatively correlated to emotional engagement as these negative emotions may work as avoidance strategies. However, as shown in Table 5, there were significant positive correlations between guilt (TRGI) and initial emotional engagement (pre SUDs) and between guilt (TRGI) and mean emotional engagement (mean SUDs) such that greater guilt was related to higher anticipatory SUDs as well as higher average SUDs throughout the session. Anger was not significantly associated with emotional engagement.

\section{Does anger or guilt predict emotional engagement in the first exposure}

session? Two hierarchical multiple regressions were used to investigate whether guilt at baseline was able to predict 1.) anticipatory and 2.) average emotional engagement in the first imaginal exposure session when controlling for PTSD severity at baseline. Because 
anger was not significantly correlated with emotional engagement, anger was excluded from this analysis. In the first hierarchal multiple regression analysis, PTSD severity (baseline PSSI) was entered at Step 1, explaining 7.1\% of the variance in emotional engagement. After entry of guilt (baseline TRGI) as the independent variable at Step 2, the total variance explained by the model as a whole was $9.3 \%, \mathrm{~F}(2,90)=4.60, p=.013$. Contrary to our hypothesis, our measure of guilt only explained an additional $2.2 \%$ of the variance in emotional engagement after controlling for PTSD severity at baseline, $\mathrm{R}$ squared change $=.022, \mathrm{~F}$ change $(1,90)=2.21, p>.05$. These results suggest that higher PTSD severity upon starting the treatment was predictive of significantly greater anticipatory emotional engagement. However, guilt did not account for significant variance in the model beyond that of PTSD severity.

Similarly, in the second hierarchical multiple regression analysis, examining average emotional engagement, PTSD severity (baseline PSSI) was entered at Step 1, explaining a non-significant $3.9 \%$ of the variance in average emotional engagement. After entry of guilt (baseline TRGI) as the independent variable at Step 2, the total variance explained by the model as a whole was $6.8 \%, \mathrm{~F}(2,88)=3.23, p>.05$. These results suggest that neither PTSD nor guilt severity prior to treatment was predictive of average level of emotional engagement throughout the initial imaginal exposure session.

In subsequent post hoc analyses, we examined the relationship between those classified as "very" angry or "very" guilty; individuals with scores on the STAXI and TRGI at least one standard deviations from the mean score, and emotional engagement. We examined zero order correlations between baseline anger (STAXI scores two standard deviations above the mean) and emotional engagement (SUDs) and between 
baseline guilt (TRGI scores one standard deviation above the mean) and emotional engagement (SUDs). There were no significant correlations between emotional engagement and baseline guilt at least one standard deviation above the mean. In terms of the relationship between emotional engagement and more severe anger, at least two standard deviations from the mean, results indicated a significant negative correlation between anger and duration of the imaginal exposure $(r=-.76, p=.046)$. This suggests that those individuals with more severe anger at baseline, two standard deviations above the mean level of anger, tended to spend less time doing the initial imaginal exposure than those less angry.

\section{Aim 3: Anger, Guilt and Treatment Outcome}

Are anger and guilt predictors of worse treatment outcome? We hypothesized

that anger and guilt would be general predictors of worse treatment outcome regardless of treatment condition. Hierarchal multiple regression was used to investigate whether severity of pretreatment anger and guilt predicted PTSD severity at posttreatment while controlling for the initial PTSD severity. PTSD severity at baseline (PSS-I) was entered as the independent variable in Step 1 and anger (STAXI) and guilt (TRGI) were entered as independent variables in Step 2. As shown in Table 7, contrary to our hypothesis, results showed that neither initial anger nor guilt was predictive of worse treatment outcome, only initial PTSD severity explained significant variance in the model.

Given the relationship between depression, PTSD, anger and guilt, in post hoc analyses we examined whether anger and guilt were predictors of worse outcome for depression, as measured by the BDI. Hierarchal multiple regression analysis was used to investigate whether severity of pretreatment anger (STAXI) and guilt (TRGI) predicted 
depression severity (BDI) at posttreatment while controlling for the possible effect of pretreatment depression severity. Anger and guilt were not found to be significant predictors of worse treatment outcome for depression when controlling for pretreatment depression severity, $R$ squared change $=.02, F$ change $(2,151)=1.45, p=.24$.

As anger and guilt were not found to be predictors of PTSD or depression outcome, we thought it necessary to investigate whether anger and guilt were impacted by treatment. Subsequent post hoc tests were run to examine the effects of treatment on anger and guilt. Paired sample t-tests were conducted to compare anger and guilt from pre to post treatment. In terms of anger scores, the mean score for anger at posttreatment $(\mathrm{M}=12.35, \mathrm{SD}=5.33)$ was significantly lower than that at pretreatmet $(\mathrm{M}=14.55, \mathrm{SD}$ $=6.48)$, suggesting that treatment had a significant, small effect on severity of anger, $\mathrm{t}(151)=4.35, \mathrm{p}<.01, d=.37, r=.18$. Similarly, the mean score for guilt at posttreatment $(\mathrm{M}=1.39, \mathrm{SD}=1.01)$ was significantly lower than that at pretreatment $(\mathrm{M}=2.11, \mathrm{SD}=1.14)$, suggesting that treatment had small, significant effect on severity of guilt, $\mathrm{t}(145)=7.75, \mathrm{p}<.01, d=.66, r=.32$. These post hoc analyses suggest that anger and guilt are impacted by treatment for PTSD. In examining whether there was a difference in treatment outcome based on treatment group, (prolonged exposure therapy verses sertraline), an independent-samples t-test was conducted to compare the anger and guilt scores for PE and SERT at baseline and at posttreatment. There were no significant differences in anger scores for PE $(M=14.55, S D=6.65)$ and SERT $(M=$ $14.01, S D=5.96 ; t(197)=.58, p=.56)$ nor guilt scores for $\mathrm{PE}(M=2.15, S D=1.09)$ and SERT $(M=2.03, S D=1.27 ; t(192)=.71, p=.48)$. However, at posttreatment, guilt scores were significantly different for $\mathrm{PE}(\mathrm{M}=1.23, \mathrm{SD}=.83)$ and SERT $(M=$ 
$1.69, S D=1.19 ; t(91.69)=-2.58, p=.01)$. Anger scores were not significantly different for PE $(\mathrm{M}=11.79, \mathrm{SD}=4.38)$ and $\operatorname{SERT}(M=13.20, S D=6.47 ; t(94.17)=-1.48, p=$ .14). This significant finding for guilt indicates that prolonged exposure therapy is more effective in reducing trauma-related guilt than sertraline.

To further investigate the impact of PTSD treatment on guilt and anger severity, we used independent t-tests to compare posttreatment anger and guilt between those with or without a PTSD diagnosis at posttreatment. The independent t-tests revealed that there was a significant difference in the severity of anger of those with a PTSD diagnosis at posttreatment $(\mathrm{M}=17.70, \mathrm{SD}=9.04)$ and those who lost their PTSD diagnosis $(\mathrm{M}=11.03, \mathrm{SD}=2.65), \mathrm{t}(30)=-4.00, p=.00)$. The magnitude of the difference in the means (mean difference $=-6.67,95 \% \mathrm{CI}:-10.07$ to -3.26 ) was between small and medium $(d=1.00, r=.44)$. The same independent t-test we calculated for guilt with results indicating that there was a significant difference in the severity of guilt of those with a PTSD diagnosis at posttreatment $(\mathrm{M}=1.99, \mathrm{SD}=1.25)$ and those who lost their PTSD diagnosis $(\mathrm{M}=1.26, \mathrm{SD}=.88), \mathrm{t}(35)=-2.98, p=.005)$. The magnitude of the difference in means (mean difference $=-.73,95 \%$ CI: -1.23 to -.23$)$ was small $(d$ $=.67, r=.32$ ). The results of these t-tests suggest that those who no longer meet diagnostic criteria for PTSD after treatment also have significantly lower levels of anger and guilt. A Chi-square test for independence (with Yates Continuity Correction) indicated no significant association between treatment group (PE verses SERT) and PTSD diagnostic status at posttreatment, $\chi^{2}(1, n=200)=3.63, p=.06$, phi $=.15$, although there was a trend toward significance. These post hoc analyses further 
describe our sample in terms of improvement of anger and guilt over the course of treatment.

Does emotional engagement mediate the relationship between anger and guilt at baseline and PTSD severity at treatment outcome? Given that anger and guilt were not significant predictors of PTSD severity at outcome, nor were they consistently related to engagement, we did not conduct the mediation analyses to determine whether emotional engagement mediated the relationship between pretreatment anger and/or guilt and PTSD severity at outcome. Despite anticipatory distress related to guilt, results indicate anger and guilt are not associated with emotional disengagement.

\section{Discussion}

The present study examined the relationship between anger, guilt, PTSD and cooccurring depression symptoms throughout the course of treatment and perhaps most importantly, whether anger and guilt hinder emotional engagement in imaginal exposure, which is known to be essential to successful PTSD treatment. Although previous research has shown anger and guilt to be related to avoidance (Street et al., 2005; Ehlers \& Clark, 2000; Henning \& Frueh, 1997), a potential mechanism by which anger and guilt could affect the course of PTSD treatment, the data from this study suggested that anger and guilt do not have a significant effect on emotional engagement in the initial imaginal exposure session nor on PTSD treatment outcome. In fact, our data suggested that higher guilt at baseline was related to higher anticipatory and average emotional engagement throughout the initial imaginal exposure. In essence, the data argued against clinical concerns that patients with more severe anger and guilt will not be able to emotionally handle prolonged exposure therapy and will not be as successful in PTSD treatment. The 
data speaks to a complicated relationship between anger, guilt, PTSD, and co-occurring depression as some of our original hypotheses were supported while others were not. Importantly, our results indicated that anger and guilt were not predictors of worse treatment outcome, and anger and guilt did show significant improvement after PTSD treatment.

In examining trauma-related psychopathology at baseline, anger and guilt were found to be differentially related to PTSD severity, specific PTSD symptoms, and cooccurring depression. The hypothesis that initial level of PTSD severity would be positively associated with baseline levels of anger and guilt was partially supported. Our results indicated that PTSD severity and guilt at baseline were positively associated, but PTSD severity and anger at baseline were not significantly associated. This is contrary to research that has found a pronounced link between PTSD and anger (e.g. Jakupcak et al., 2007; Olantunji, Ciesielski, \& Tolin, 2010). Our missing link between anger and PTSD at baseline could have simply been telling of the anger measure used or a specific characteristic about the sample. For instance, a recent study examining the clinical presentation of PTSD in survivors of interpersonal assault has shown men to experience elevated state anger in comparison to women (Galovski, Mott, Yinong, \& Resick, 2012). In the same sample, gender differences were not seen for guilt related to PTSD (Galovski, Mott, Yinong, \& Resick, 2012). In our sample, we did not find any gender differences in mean scores of guilt or anger at baseline, so it is conceivable that our sample was simply not as acutely angry as other PTSD samples. As shown in Table 1, the mean state anger score for our total sample is 14.32 , which is lower than that reported by other studies 
examining anger in individuals with PTSD (e.g. Galovski, Mott, Yinong, \& Resick, 2011; Riggs et al., 1992).

The difference between the relationships of anger and guilt to PTSD severity in our sample might also indicate that these emotions are not as similar as initially hypothesized. Previously, we suggested that anger and guilt's similar association to worse severity and experience of PTSD (e.g., Taylor et al, 2001; Ehlers et al., 1998; Foa et al., 1995) could be due to anger and guilt being functionally similar. Given that only guilt was significantly associated with PTSD severity at baseline, our initial hypothesis needs to be altered to better explain the relationship between anger, guilt, and PTSD symptomology. One possible explanation is that anger and guilt are related to another negative emotion, such as shame. Some research has explored the question of whether guilt and shame each have an independent relationship to anger, and whether anger may be a secondary response to shame (Tangney, Wagner, Fletcher, et al., 1992). Although we did not measure shame in this sample, investigating the relationship between anger, shame, guilt and PTSD symptomology would be an important step to further delineating this complicated and overlapping emotions related to PTSD symptomology.

In breaking down the PTSD subscales, the hypothesis that the Simms et al. (2002) avoidance subscale would be related to anger and guilt at baseline was also partially supported. There was a positive trend between the avoidance subscale and guilt at baseline; however, we did not find a relationship in our sample between the avoidance subscale of symptoms and anger. Again, this may be a result of our measure of state anger in general verses a trauma-specific measure of anger or our sample not being as generally "angry" as other PTSD samples. The lack of a relationship between avoidance 
symptoms and anger might also mean that, for our sample, state anger did not play a role in PTSD symptomology prior to treatment. In further examination of the other PTSD subscales, results indicated that the intrusions and dysphoria subscales were positively related to guilt at baseline. This is an interesting finding in developing a more nuanced understanding of specific PTSD symptoms that are positively associated with guilt as no studies to date have found that guilt is associated with specific PTSD symptom clusters. In examining the significant baseline associations between guilt and PTSD, we wanted to understand what, if any, role depression played in this relationship. As prior research has demonstrated a positive association between severity of guilt and severity of PTSD symptoms (e.g. Henning \& Frueh, 1997) as well as a link between guilt and increased avoidance (Street et al., 2005; Ehlers \& Clark, 2000; Henning \& Frueh, 1997), we hypothesized that depression would mediate the relationship between the avoidance cluster of symptoms and guilt. Notably, our results indicated that depression did mediate the relationship between overall PTSD severity and guilt, as well as the specific relationships between the dysphoria and intrusive symptoms and guilt. However, contrary to our original hypothesis depression was not found to mediate the relationship between avoidance symptoms and guilt.

These significant mediation models with the intrusions and dysphoria symptom clusters are important for understanding PTSD symptoms exacerbated by guilt as well as the mechanism by which guilt persists in individuals with chronic PTSD. The relationship between the dysphoric and intrusive symptoms and guilt may reflect shared ruminative tendencies (e.g. Elwood et al., 2009). Rumination is defined as the tendency to think repetitively and passively about negative emotions, precipitators of negative 
events, symptoms of distress, and worry about the meaning of distress (Nolen-Hoeksema, 1991), and rumination was initially related to depressive symptoms and disorders (NolenHoeksema, 2000; Davis \& Nolen-Hoeksema, 2000). Moreover, rumination has been posited as a cognitive factor that is likely to lead to the perception of ongoing threat and therefore to the maintenance of PTSD symptoms (Ehlers \& Clark, 2000). As a cognitive avoidance strategy, trauma survivors may ruminate in an attempt to avoid memories of the trauma itself (Michael et al., 2007), in doing so preventing the processing of the trauma memories and leading to increased re-experiencing symptoms (Ehlers, Mayou, \& Bryant, 1998).

Our significant mediation models suggest that the relation between the PTSD intrusions and dysphoria symptom clusters and trauma-related guilt could be explained in significant part by co-occurring depression. It is possible that rumination about the traumatic event, such as repetitively thinking about why the trauma occurred or what if things had happened differently, led to feeling more guilt about the trauma by way of depressive symptomology. Others have theorized that negative feelings experienced while ruminating may trigger more intrusive memories, which then require further rumination, resulting in a cyclical process (Michael et al., 2007). Moreover, research has shown ruminative thoughts to function as a way to avoid or blunt painful affective experiences (e.g. Michael et al., 2007; Fresco et al., 2002), such as guilt. Although others have suggested that rumination might be the psychological mechanism through which PTSD increases anger after a trauma (Orth et al., 2008), this did not seem to be the case for our sample in terms of anger. Perhaps, rumination affects the experience of anger and guilt in individuals with PTSD in distinct ways. 
On the other hand, the significant mediation models may also have reflected symptom overlap between PTSD and depression or worse symptomology overall (e.g. Post et al., 2011). Previous research has shown that in comparison to those with PTSD alone, individuals with PTSD and co-occurring depression had elevated dysphoria and reexperiencing symptoms and higher levels of negative affect (Post et al., 2011). It would be desirable for future studies to examine how rumination fits into this model and develop a path for how these variables are related.

In sum, the results of this first aim suggest a significant relationship between the intrusions and dysphoria PTSD subscales and guilt that is mediated by depression. Rumination has been found to predict the occurrence and chronicity of depression and anxiety symptoms (Nolen-Hoeksema, 2000) as well as PTSD (Michael et al., 2007). This significant relationship and the weaker relationship between guilt and the PTSD avoidance subscale could mean that cognitive avoidance in the form of rumination is a key factor in understanding the relationship between guilt, PTSD, and depression. Alternatively, these results could imply that depression and PTSD symptoms overlap in the form of guilt. Guilt and depression are highly correlated (Marx et al., 2010) and individuals with comorbid depression tend to show more severe symptoms than either disorder alone (Blanchard, Buckley, Hickling, \& Taylor, 1998; Post, Zoellnor, Youngstrom, \& Feeny, 2011). In order to get a more nuanced understanding of the role of guilt and anger in PTSD symptomology, these possible explanations need further investigation. Additionally, clinicians' ability to target specific PTSD symptoms related to both guilt and depression would be clinically advantageous. 
In examining the role of anger and guilt on emotional engagement, our data clearly suggested that anger and guilt at baseline were not strongly associated with emotional engagement in the first session of imaginal exposure. Emotional engagement during exposure sessions has proven to be crucial for treatment success (Foa et al., 1995; Jaycox, Foa, \& Morral, 1998) particularly during the initial imaginal exposure because the intensity of the emotional (fear) response to the trauma memory tends to decrease across sessions (Foa \& Kozak, 1986). Based on previous literature linking anger and guilt to increased avoidance (Street et al., 2005; Ehlers \& Clark, 2000; Henning \& Frueh, 1997), we hypothesized that anger and guilt would be negatively correlated with emotional engagement at the first session of imaginal exposure. Our findings indicated that baseline anger was not significantly associated with anticipatory, peak, or post emotional engagement in the form of level of distress or discomfort experienced. Notably, guilt was associated with higher anticipatory imaginal exposure emotional engagement levels (i.e., engagement prior to exposure) as well as average emotional engagement throughout the imaginal exposure. Thus, higher guilt at baseline is associated with more intense initial and average emotional engagement. This means that having trauma-related guilt at the start of treatment is not related to a lack of emotional engagement as we once suspected.

This finding has important clinical implications, as previous work has suggested that guilt is related to avoidance as a coping strategy potentially interfering with PTSD recovery (Held et al., 2011; Street et al., 2005). A recent study examined disengagement coping as a partial mediator between trauma-related guilt and severity of PTSD in a sample of 175 veterans entering residential PTSD treatment with either PTSD or 
subthreshold PTSD (Held et al., 2011). The authors found that disengagement coping partially mediated the relationship between guilt and self-reported PTSD severity but did not mediate the relationship when PTSD severity was based on clinicians' ratings. Similar to Street et al.'s (2005) contention that higher guilt-related cognitions are related to increases in the use of avoidant coping strategies interfering with PTSD recovery, these results indicated a significant relationship between PTSD severity, guilt, and lack of emotional engagement. However, our results indicated that having guilt at baseline does not necessarily indicate a propensity for avoidance or emotional disengagement as a coping strategy during imaginal exposure. Perhaps there are other factors involved in this relationship, such as a distinction between guilt and shame, that may lead some individuals with chronic PTSD to avoid as a form of coping, while others sustain emotional engagement. For example, Tangney and colleagues (2002) have observed that feelings of shame have been found to motivate avoidant coping, so it is possible that shame rather than guilt is more likely to result in avoidance. Further investigation into these highly related negative emotions is required to understand how they are related to PTSD symptomology.

There are preconceived clinical notions about who "can" and "cannot" do exposure therapy (Pitman et al., 1991; Tarrier et al., 1999). Tolerability and safety have been of the utmost concern since prolonged exposure therapy was developed, and there has been specific concern that the high levels of distress that may occur during imaginal exposure may result in an exacerbation of symptoms and patients potentially getting worse because of treatment (Pitman et al., 1991; Tarrier et al., 1999; Cahill et al., 2006). Anger and guilt are strong negative emotions that have been shown to contribute to 
persistence and maintenance of PTSD and depression symptoms post-trauma (Kubany et al., 1996; Foa et al., 1995), thus it would seem clinically relevant to be wary of these emotions prior to starting imaginal exposure. The results of the current study show that PTSD severity accounts for only $7 \%$ of the variance in emotional engagement based on our measure of SUDs and adding guilt to the model only increased this variance by $2 \%$. This means that despite anticipatory distress related to guilt, anger and guilt are generally not associated with worse emotional engagement in the first imaginal exposure session, as our subjective ratings of distress do not indicate a negative relationship. In our sample, participants with varying levels of anger and guilt did not experience a difference in their ability to emotionally engage. Although we hypothesized anger and guilt as possible avoidance strategies that cause clients to have trouble engaging with the prolonged imaginal exposures, these results show that clients with more pronounced anger and guilt are not struggling to emotionally engage with their trauma memory. This is good news for clinicians concerned with the presumably negative effects of starting prolonged exposure therapy with individuals with higher negative emotions, such as anger or guilt, at the start of therapy.

In post hoc analyses, we more closely examined those with the most severe anger and guilt, as it may be those clients for whom emotional engagement is impacted. One potentially important finding related to individuals deemed "very angry" was that they tended to have shorter durations of their first imaginal exposure session. Prolonged exposure therapy requires repeated imaginal exposure sessions in order to bring about habituation to the trauma memory (Foa et al., 1995; Jaycox, Foa, \& Morral, 1998). However, research has shown that shorter, 30-minute, imaginal exposure sessions were 
just as effective as longer, 60-minute sessions (van Minnen \& Foa, 2002). We did not examine outcome specifically for these "very angry" individuals, as previous research has not shown shorter imaginal exposures to be related to treatment outcome (van Minnen \& Foa, 2002). However, it is possible that more intense anger makes it more difficult for the therapist to keep them engaged for as long a period of time. Future research is needed to replicate this finding and further examine whether anger can affect the relationship between client and therapist during imaginal exposures specifically.

In sum, results from our second aim suggest that neither severity of PTSD symptoms nor strong negative emotions, such as anger and guilt, hinder emotional engagement in the initial imaginal exposure. As stated earlier, Foa et al. (1995) found that trauma survivors who experienced more fear during prolonged exposure had better treatment outcomes, meaning that distress during imaginal exposure is related to emotional engagement to the trauma memory. Further, Jaycox, Foa, and Morral (1998) indicated that high initial engagement, as well as gradual between-session habituation were critical aspects of exposure therapy for PTSD. Therefore, it is important to recognize that strong negative emotions, such as guilt, are not necessarily counterproductive to the treatment process, and could, in fact, help to contribute to better emotional engagement, at least initially

In our third aim, we hypothesized that anger and guilt would be general predictors of worse treatment outcome regardless of treatment condition as studies have shown anger and guilt to hinder treatment for chronic PTSD for some individuals (e.g. Ehlers, Clark, et al., 1998; Taylor et al., 2001; Davidson et al., 2004). However, our results suggested that neither initial anger nor guilt were predictive of worse outcome. 
Furthermore, not only were anger and guilt not significant predictors of treatment outcome, our post hoc analyses suggested that anger and guilt improved over the course of treatment. Other studies have found similar results with anger and guilt improving as a result of PTSD treatment (Cahill et al., 2003; Nishith, Nixon, \& Resick, 2002). In post hoc analysis, it was also found that guilt was more effectively improved by prolonged exposure therapy than pharmacotherapy for PTSD. There are no studies to date that have evidenced this difference in guilt in treatment for PTSD, and further research into this area is needed to better understand what type of treatment is best fit to certain individuals based on their clinical presentation. Matching the most effective treatment to the individual is of utmost importance as people tend to have clear preferences for specific treatments, potentially impacting treatment outcome (Feeny,et al., 2009; Pyne et al., 2005). If trauma-related guilt is in fact more effectively treated by exposure therapy verses pharmacotherapy for PTSD, this would be an important point to make with those individuals seeking treatment.

Given the relationship between emotional engagement in PTSD therapy and treatment outcome (Foa et al., 1995), we hypothesized that emotional engagement would mediate the relationship between baseline level of anger or guilt and treatment outcome, meaning that higher emotional engagement would lead to better treatment outcome. Previous research on clinical complexities frequently seen in patients with chronic PTSD, such as diagnostic co-occurrence and complicated histories, have not been found to translate into less tolerability of imaginal exposure. Although our results did not support emotional engagement as a mediator between baseline anger and guilt and treatment 
outcome, the current study further delineates these findings in that patients with higher levels of guilt in anger can both tolerate and benefit from imaginal exposure.

In summary, depression emerged as a mediator between PTSD symptoms and guilt at baseline, implying a relationship between guilt and specific PTSD symptoms of intrusions and dysphoria. In contrast, depression was not found to mediate the relationship between anger and PTSD symptoms at baseline. Neither anger nor guilt played a significant role in emotional disengagement during the first imaginal exposure session, meaning that clinicians do not need to be overly concerned when starting prolonged imaginal exposures with patients with more intense anger and guilt prior to treatment. Although anger and guilt were not predictors of treatment outcome, anger and guilt were significantly different between those who still rendered a diagnosis of PTSD upon completing treatment (either PE or SER) and those who no longer met diagnostic criteria upon completing treatment. Furthermore, anger and guilt tended to be significantly improved upon completing treatment. Clients deemed clinically "complex" due to increased anger and guilt were able to engage in imaginal exposure and to benefit from treatment.

\section{Limitations and Future Directions}

Although this study contributes to the existing knowledge about PTSD symptoms and their relationship to anger and guilt, several limitations should be kept in mind when interpreting the results. The study was cross-sectional nature, not showing temporal precedence (Vogt, King, \& King, 2007), meaning that we are unable to say whether anger and guilt preceded PTSD or were a result of PTSD severity. Although guilt was found to be related to PTSD at baseline, longitudinal research is also needed to determine whether 
guilt leads to the development of PTSD and depression symptoms or if PTSD and depression leads to the development of guilt. For instance, it is possible that individuals begin with clinical levels of anger and guilt that leads to depression and in turn affects the clinical presentation of their PTSD symptoms. To establish causal roles of guilt and anger on PTSD severity, it will be important to conduct longitudinal research that investigates the effects of pretreatment levels of guilt and anger on posttreatment PTSD and depression severity. In addition, utilizing path analysis would useful to investigate the relationships between guilt, anger, PTSD and co-occurring depression at baseline.

Another limitation of the current study is that our measure of guilt is a trauma specific measure, whereas our measure of anger is a state anger rating. We used state anger as the best possible measure of how individuals were describing their anger at the moment in which they were completing the self-report. Although the participants were asked to focus on how they have been feeling in regard to their PTSD symptoms, this measure of anger could be confounded by other variables out of the control of the research team, such as the participant being angered by a family member prior to their initial session. Exploring the other anger variables, such as trait anger, anger in, anger out and anger control as measured by the STAXI, could help to better delineate the relationship between anger and PTSD symptomology throughout the treatment process.

Despite the limitations of this study, the findings have several implications for future research. Future studies should examine changes in anger and guilt over the course of therapy, perhaps tracking from session to session to get a better idea of whether anger or guilt act as a hindrance to the therapy process or the therapeutic alliance between client and therapist. Tracking in-session and between session changes in anger and guilt 
would be helpful in further alleviating fears in clinicians about performing imaginal exposures with clients with more intense negative emotionality prior to starting therapy.

To conclude, the data presented in the current study should be an encouragement to clinicians wanting to utilize prolonged exposure therapy to treat their clients with chronic PTSD, even if they have clinically concerning anger or guilt related to their experience of PTSD. The data suggested that anger and guilt do not hinder emotional engagement with imaginal exposure and thereby do not create a barrier against effective PTSD treatment. And importantly, anger and guilt will likely decrease as a result of PTSD treatment with prolonged exposure. Although, debilitating anger and guilt may draw attention to therapists, perhaps make them wary of starting imaginal exposure, it does not appear that anger or guilt affects the tolerability of this treatment. These findings provide further evidence for the broad applicability of prolonged exposure therapy and help to provide a more nuanced understanding of how anger and guilt influence PTSD throughout the treatment process. 


\section{A. Direct Effect:}

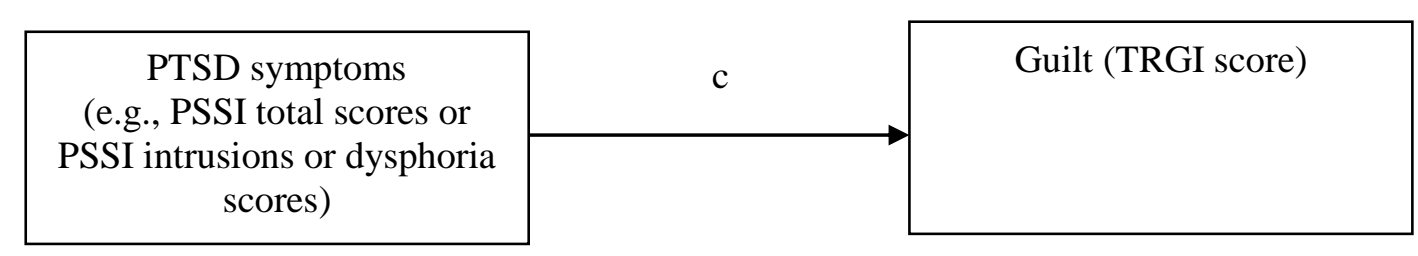

B. Indirect Effect:

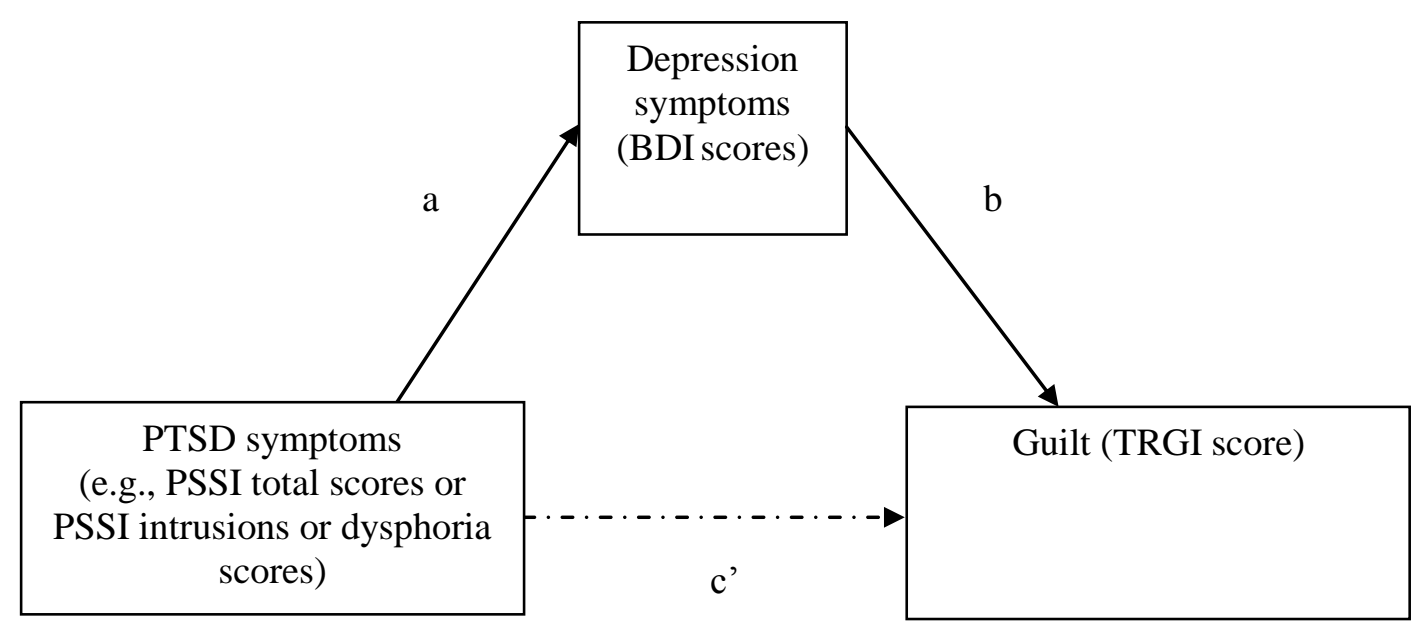

Figure 1. (A) The regression coefficient indicating a direct effect of PTSD symptoms on guilt. (B) Regression coefficients indicating an indirect effect of PTSD symptoms on guilt through the proposed mediator (depression symptoms). When $c-c$ ' (i.e., $a^{*} b$ ) is significant, there is evidence of mediation. 
Table 1

Means and Standard Deviations of PTSD Symptoms, Anger Symptoms, Guilt Symptoms, and Depression Symptoms at Pre-and Posttreatment.

\begin{tabular}{lcccccc}
\hline & \multicolumn{2}{c}{ Pretreatment } & \multicolumn{3}{c}{ Posttreatment } \\
Measure & $M$ & $S D$ & Range & $M$ & $S D$ & Range \\
\hline PTSD Severity (PSS-I) & 29.57 & 6.69 & $15-46$ & 15.69 & 12.27 & $0-46$ \\
Anger (STAXI) & 14.32 & 6.36 & $10-40$ & 12.35 & 5.33 & $10-40$ \\
Guilt (TRGI) & 2.10 & 1.17 & $0-4$ & 1.40 & 1.00 & $0-4$ \\
Depression (BDI-I) & 25.03 & 9.78 & $4-48$ & 12.94 & 12.02 & $0-54$ \\
\end{tabular}

Note. PSS-I = PTSD Symptom Scale Interview; STAXI = State-Trait Anger Expression Inventory; TRGI = Trauma-Related Guilt Inventory; BDI = Beck Depression Inventory. 
Table 2

Correlations among PTSD, Anger, Guilt, and Depression Measures

\begin{tabular}{|c|c|c|c|c|c|c|c|c|}
\hline & 1. & 2. & 3. & 4. & 5. & 6. & 7. & 8. \\
\hline 1. PSS-I total & - & & & & & & & \\
\hline 2. Intrusions & $.69 * *$ & - & & & & & & \\
\hline 3. Avoidance & $.57 * *$ & $.39 * *$ & - & & & & & \\
\hline 4. Hyperarousal & $.47 * *$ & $.21 * *$ & .13 & - & & & & \\
\hline 5. Dysphoria & $.79 * *$ & $.23 * *$ & $.29 * *$ & $.15^{*}$ & - & & & \\
\hline 6. STAXI & .11 & .11 & -.00 & .00 & .11 & - & & \\
\hline 7. TRGI & $.21 * *$ & $.21 * *$ & .14 & -.04 & $.17 *$ & .06 & - & \\
\hline 8. BDI-I & $.49 * *$ & $.34 * *$ & $.17 *$ & .11 & $.47 * *$ & $.35 * *$ & $.39 * *$ & - \\
\hline
\end{tabular}

Note. $* * p<.01 ; * p<.0$ 
Table 3

Regression Coefficients and Bootstrapped Point Estimates Examining Depression a Mediator between PTSD Symptoms and Guilt at Baseline

\begin{tabular}{|c|c|c|c|c|c|c|c|c|}
\hline \multirow[b]{2}{*}{$\begin{array}{l}\text { Dependent } \\
\text { Variable } \\
\text { (Independent } \\
\text { Variable) }\end{array}$} & \multirow[b]{2}{*}{ Path } & \multicolumn{3}{|c|}{ Normal Theory Tests } & \multicolumn{4}{|c|}{$\begin{array}{l}\text { Bootstrapping Results for } \\
\text { Indirect Effects }(95 \% \mathrm{CI})\end{array}$} \\
\hline & & B & $S E$ & $t$ & $\begin{array}{l}\text { Point } \\
\text { Estim } \\
\text { ate }\end{array}$ & $\mathrm{SE}$ & $\begin{array}{c}\text { Lowe } \\
\text { r }\end{array}$ & $\begin{array}{c}\text { Upp } \\
\text { er }\end{array}$ \\
\hline \multirow{5}{*}{ Guilt (Intrusions) } & $\mathrm{a}$ & .09 & .03 & $3.00 * *$ & & & & \\
\hline & b & 1.19 & .24 & $4.96 * *$ & & & & \\
\hline & $\mathrm{c}$ & .04 & .01 & $5.15^{* *}$ & & & & \\
\hline & $c^{\prime}$ & .04 & .03 & 1.27 & & & & \\
\hline & $a * b$ & & & & $.05 * *$ & .01 & .02 & .08 \\
\hline \multirow[t]{5}{*}{ Guilt (Dysphoria) } & $\mathrm{a}$ & .05 & .02 & $2.36 * *$ & & & & \\
\hline & $\mathrm{b}$ & 1.11 & .16 & $7.04 * *$ & & & & \\
\hline & $\mathrm{c}$ & .05 & .01 & $5.33 * *$ & & & & \\
\hline & $c^{\prime}$ & -.00 & .02 & -.17 & & & & \\
\hline & $a * b$ & & & & $.05 * *$ & .01 & .03 & .08 \\
\hline \multirow[t]{5}{*}{ Guilt (Avoidance) } & $\mathrm{a}$ & .12 & .06 & 1.95 & & & & \\
\hline & $\mathrm{b}$ & 1.11 & .53 & $2.08 *$ & & & & \\
\hline & $\mathrm{c}$ & .04 & .01 & $5.67 * *$ & & & & \\
\hline & $c^{\prime}$ & .07 & .06 & 1.23 & & & & \\
\hline & $a * b$ & & & & .05 & .03 & .00 & .10 \\
\hline \multirow[t]{5}{*}{ Guilt (Total PSSI) } & $\mathrm{a}$ & .04 & .01 & $2.92 * *$ & & & & \\
\hline & $\mathrm{b}$ & .70 & .09 & $7.46^{* *}$ & & & & \\
\hline & $\mathrm{c}$ & .05 & .01 & $5.03 * *$ & & & & \\
\hline & $c^{\prime}$ & .00 & .01 & .34 & & & & \\
\hline & $a * b$ & & & & $.03 * *$ & .01 & .02 & .05 \\
\hline
\end{tabular}

Note. 1,000 bootstrap samples; The mediator is significant at $p<.05$ if the $C I$ does not contain zero; ${ }^{*} p<.05 ; * * p<.01$. See Figure 1 and the article text for a description of each path. 
Table 4

Correlations among Anger, Guilt, and Emotional Engagement Measures

\begin{tabular}{|c|c|c|c|c|c|c|}
\hline & 1. & 2. & 3. & 4. & 5. & 6. \\
\hline 1. STAXI (State) & - & & & & & \\
\hline 2. TRGI & .08 & - & & & & \\
\hline 3. Initial SUDs & .09 & $.21 *$ & - & & & \\
\hline 4. Peak SUDs & .18 & .15 & $.58 * *$ & - & & \\
\hline 5. Post SUDs & .08 & .17 & $.39 * *$ & $.65 * *$ & - & \\
\hline 6. Mean SUDs & .12 & $.21 *$ & $.66 * *$ & $.88 * *$ & $.79 * *$ & - \\
\hline
\end{tabular}


Table 5

Regression Analyses Predicting Initial and Mean Emotional Engagement from Pretreatment PTSD Severity and Guilt $(N=94)$

\begin{tabular}{lccc}
\hline Initial Emotional Engagement & B & SE B & $\beta$ \\
\hline Step 1 & .94 & .36 & .27 \\
Pretreatment PTSD Severity & & & \\
Step 2 & .79 & .37 & $.22^{*}$ \\
Pretreatment PTSD Severity & 3.46 & 2.33 & .16 \\
Guilt & & & \\
\hline
\end{tabular}

Mean Emotional Engagement

Step 1

Pretreatment PTSD Severity .56 .29

.20

Step 2

Pretreatment PTSD Severity $.46 \quad .30 \quad .16$

Guilt $2.82 \quad 1.70$ .18

Note. $* * p<.01 ; * p<.05$. For initial emotional engagement, $\mathrm{R}^{2}=.07$ for Step $1, \Delta \mathrm{R}^{2}$ $=.02$ for Step 2. For mean emotional engagement, $R^{2}=.04$ for Step $1, \Delta R^{2}=.03$ for Step 2 
Table 6

Regression Analyses Predicting Treatment Outcome from Pretreatment Anger and Guilt when Controlling for Pretreatment PTSD Severity $(N=200)$

\begin{tabular}{llll}
\hline Predictors & B & SE B & $\beta$
\end{tabular}

Step 1

Pretreatment PTSD Severity

$.13 \quad .30 * *$

Step 2

$\begin{array}{llll}\text { Anger } & .11 & .13 & .06 \\ \text { Guilt } & -.66 & .74 & -.06\end{array}$

Note. $* * p<.01 ; * p<.05, \mathrm{R}^{2}=.09$ for Step $1, \Delta \mathrm{R}^{2}=.01$ for Step 2 


\section{References}

American Psychological Association. (2000). Diagnostic and statistical manual of mental disorders (4th ed., text rev). Washington, DC: Author.

Andrews, B., Brewin, C. R., Rose, S., \& Kirk, M. (2000). Predicting PTSD symptoms in victims of violent crime: The role of shame, anger, and childhood abuse. Journal of Abnormal Psychology, 109(1), 69-73. doi:10.1037/0021-843x.109.1.69

Baron, R. M., \& Kenny, D. A. (1986). The moderator-mediator variable distinction in social psychological research: Conceptual, strategic, and statistical considerations. Journal of Personality and Social Psychology, 51(6), 1173-1182. doi:10.1037/0022-3514.51.6.1173

Baumeister, R. F., Stillwell, A. M., \& Heatherton, T. F. (1994). Guilt. Psychological Bulletin, 115(2), 243-267. doi:10.1037//0033-2909.115.2.243

Beck, A. T., Steer, R. A., \& Garbin, M. G. (1988). Psychometric properties of the Beck Depression Inventory: Twenty-five years later. Clinical Psychology Review, 8, $77-100$.

Beck, A. T., Ward, C. H., Mendelson, M., Mock, J., \& Erbaugh, J. (1961). An inventory for measuring depression. Archives of General Psychiatry, 4(6), 561-571. doi:10.1001/archpsyc.1961.01710120031004

Blanchard, E. B., Buckley, T. C., Hickling, E. J., \& Taylor, A. E. (1998). Posttraumatic stress disorder and comorbid major depression. Journal of Anxiety Disorders, 12(1), 21-37.

Brady, K., Pearlstein, T., Asnis, G. M., Baker, D., Rothbaum, B., Sikes, C. R., \& Farfel, G. M. (2000). Efficacy and safety of sertraline treatment of posttraumatic stress 
disorder. JAMA: The Journal of the American Medical Association, 283(14), 1837-1844. doi:10.1001/jama.283.14.1837

Breslau, N., Davis, G. C., Andreski, P., \& Peterson, E. (1991). Traumatic events and Ppttraumatic stress disorder in an urban population of young adults. Archives of General Psychiatry, 48(3), 216-222. doi:10.1001/archpsyc.1991.01810270028003

Bryant, R. A., \& Harvey, A. G. (1995). Processing threatening information in posttraumatic stress disorder. Journal of Abnormal Psychology, 104, 537-554.

Cahill, S. P., Rauch, S. A., Hembree, E. A., \& Foa, E. B. (2003). Effect of cognitivebehavioral treatments for PTSD on anger. Journal of Cognitive Psychotherapy, 17, 113-131. doi: 10.1891/jcop.17.2.113.57434

Cahill, S.P., Foa, E.B, Hembree, E.A., Marshall, R.D., \& Nacash, N. (2006). Dissemination of exposure therapyin the treatment of posttraumatic stress disorder. Journal of Traumatic Stress, 19(5), 597-610. doi: 10.1002/jts.20173

Chemtob, C. M., Hamada, R. S., Roitblat, H. L., \& Muraoka, M. Y. (1994). Anger, impulsivity, and anger control in combat-related posttraumatic stress disorder. Journal of Consulting and Clinical Psychology, 62(4), 827-832. doi: $10.1037 / 0022-006 x \cdot 62.4 .827$

Chemtob, C. M., Novaco, R. W., Hamada, R. S., \& Gross, D. M. (1997). Cognitivebehavioral treatment for severe anger in posttraumatic stress disorder. Journal of Consulting and Clinical Psychology, 65(1), 184-189. doi: 10.1037/0022006x.65.1.184 
Chemtob, C. M., Novaco, R. W., Hamada, R. S., Gross, D. M., \& Smith, G. (1997). Anger regulation deficits in combat-related posttraumatic stress disorder. Journal of Traumatic Stress, 10(1), 17-36.

Clohessy, S., \& Ehlers, A. (1999). PTSD symptoms, response to intrusive memories and coping in ambulance service workers. The British Journal of Clinical Psychology, $38,251-265$.

Cohen, J.W. (1988). Statistical power analysis for the behavioral sciences $\left(2^{\text {nd }}\right.$ edn). Hillsdale, NJ: Lawrence Erlbaum Associates.

Davidson, J., Landerman, L. R., \& Clary, C. M. (2004). Improvement of anger at one week predicts the effects of sertraline and placebo in PTSD. Journal of Psychiatric Research, 38(5), 497-502. doi: 10.1016/j.jpsychires.2004.01.005

Davidson, J. R.T., Landerman, L., Farfel, G., \& Clary, C. (2002). Characterizing the effects of sertraline in post-traumatic stress disorder. Psychological Medicine, 32(4), 661-670. doi:10.1017/S0033291702005469

Davidson, J. R. T., Hughes, D., Blazer, D. G., \& George, L. K. (1991). Post-traumatic stress disorder in the community: an epidemiological study. Psychological Medicine, 21(03), 713-721. doi:10.1017/S0033291700022352

Davidson, J. R. T., Rothbaum, B. O., van der kolk, B. A., Sikes, C. R., \& Farfel, G. M. (2001). Multicenter, double-blind comparison of sertraline and placebo in the treatment of posttraumatic stress disorder. Archives of General Psychiatry, 58(5), 485-492.

Davis, R. N., \& Nolen-Hoeksema, S. (2000). Cognitive inflexibility among ruminators and 
nonruminators. Cognitive Therapy and Research, 24, 699-711.

DeMoja, C. A., \& Spielberger, C. D. (1997). Anger and drug addiction. Psychological Reports, 81, 152-154.

Dunmore, E., Clark, D. M., \& Ehlers, A. (1999). Cognitive factors involved in the onset and maintenance of posttraumatic stress disorder (PTSD) after physical or sexual assault. Behaviour Research and Therapy, 37(9), 809-829. doi: 10.1016/s00057967(98)00181-8

Ehlers, A., \& Clark, D. M. (2000). A cognitive model of posttraumatic stress disorder. Behaviour Research and Therapy, 38(4), 319-345.

Ehlers, A., Clark, D. M., Dunmore, E., Jaycox, L., Meadows, E., \& Foa, E. B. (1998). Predicting response to exposure treatment in PTSD: The role of mental defeat and alienation. Journal of Traumatic Stress, 11(3), 457-471. doi: 10.1023/a:1024448511504

Ehlers, A., Mayou, R. A., \& Bryant, B. (1998). Psychological predictors of chronic posttraumatic stress disorder after motor vehicle accidents. Journal of Abnormal Psychology, 107(3), 508-519. doi: 10.1037/0021-843x.107.3.508

Ellsworth, P. C. (1994). Sense, culture, and sensibility. Emotion and culture: Empirical studies of social influence. S. Kitayama and H. R. Markus. (Eds.). Washington D.C., American Psychological Association: 23-50.

Elwood, L.S., Hahn, K.S., Olatunji, B.O., \& Williams, N.L. (2009). Cognitive vulnerabilities to the development of PTSD: A review of four vulnerabilities and the proposal of an integrative vulnerability model. Clinical Psychology Review, 29, 87-100. doi:10.1016/j.cpr.2008.10.002 
Evans, S., Giosan, C., Patt, I., Spielman, L., \& Difede, J. (2006). Anger and its association to distress and social/occupational functioning in symptomatic disaster relief workers responding to the September 11, 2001, World Trade Center disaster. Journal of Traumatic Stress, 19(1), 147-152. doi: 10.1002/jts.20107

Faul, F., Erdfelder, E., Lang, A. G., \& Buchner, A. (2007). G*Power 3: A flexible statistical power analysis program for the social, behavioral, and biomedical sciences. Behavior Research Methods, 39, 175-191.

Feeny, N. C., Zoellner, L. A., \& Foa, E. B. (2000). Anger, Dissociation, and Posttraumatic Stress Disorder Among Female Assault Victims. Journal of Traumatic Stress, 13(1), 89-100.

Feeny, N. C., Zoellner, L.A., Mavissakalian, M.R., \& Roy-Byrne, P.P. (2009). What would you choose? Sertraline or prolonged exposure in community and PTSD treatment seeking women. Depression \& Anxiety, 26(8), 724-731. doi:10.1002/da.20588

Foa, E. B., Cashman, L., Jaycox, L., \& Perry, K. (1997). The validation of a self-report measure of posttraumatic stress disorder: The posttraumatic diagnostic scale. Psychological Assessment, 9(4), 445-451. doi:10.1037/1040-3590.9.4.445

Foa, E. B., Dancu, C. V., Hembree, E. A., Jaycox, L. H., Meadows, E. A., \& Street, G. P. (1999). A comparison of exposure therapy, stress inoculation training, and their combination for reducing posttraumatic stress disorder in female assault victims. Journal of Consulting and Clinical Psychology, 67(2), 194-200. doi: 10.1037/0022-006x.67.2.194 
Foa, E. B., Franklin, M. E., \& Moser, J. (2002). Context in the clinic: how well do cognitive-behavioral therapies and medications work in combination? Biological Psychiatry, 52(10), 987-997. doi: 10.1016/s0006-3223(02)01552-4

Foa, E. B., Hembree, E. A., Cahill, S. P., Rauch, S. A. M., Riggs, D. S., Feeny, N. C., \& Yadin, E. (2005). Randomized Trial of Prolonged Exposure for Posttraumatic Stress Disorder With and Without Cognitive Restructuring. Journal of Consulting and Clinical Psychology, 73(5), 953-964. doi: 10.1037/0022-006X.73.5.953

Foa, E. B., Huppert, J. D., \& Cahill, S. P. (2006). Emotional processing theory: an update. In B. O. Rothbaum (Ed.), Pathological anxiety: emotional processing in etiology and treatment (pp. 3-24): Guilford Press.

Foa, E. B., Riggs, D. S., Dancu, C. V., \& Rothbaum, B. O. (1993). Reliability and validity of a brief instrument for assessing post-traumatic stress disorder. Journal of Traumatic Stress, 6(4), 459-473. doi: 10.1007/bf00974317

Foa, E. B., Riggs, D. S., Massie, E. D., \& Yarczower, M. (1995). The impact of fear activation and anger on the efficacy of exposure treatment for posttraumatic stress disorder. Behavior Therapy, 26(3), 487-499. doi: 10.1016/s0005-7894(05)800966

Foa, E. B., \& Rothbaum, B. (1998). Treating the trauma of rape: Cognitive behavioral therapy for PTSD. New York: Guilford Press.

Forbes, D., Creamer, M., Hawthorne, G., Allen, N., \& McHugh, T. (2003). Comorbidity as a predictor of symptom change after treatment in combat-related posttraumatic stress disorder. Journal of Nervous and Mental Disease, 191, 93-99. 
Forbes, D., Parslow, R., Creamer, M., Allen, N., McHugh, T., \& Hopwood, M. (2008). Mechanisms of anger and treatment outcome in combat veterans with posttraumatic stress disorder. Journal of Traumatic Stress, 21(2), 142-149. doi: $10.1002 /$ jts.20315

Fresco, D.M., Frankel, A.N., Mennin, D.S., Turk, C.L., \& Heimberg, R.G. (2002). Distinct and overlapping features of rumination and worry: The relationship of cognitive production to negative affective states. Cognitive Therapy Research 26 , $179-188$.

Galovski, T.E., Mott, J., Yinong, Y., \& Resick, P.A. (2011). Gender differences in the clinical presentation of PTSD and its concomitants in survivors of interpersonal assault. Journal of Interpersonal Violence, 26(4), 789-806. doi: $10.1177 / 0886260510365865$

Gibson, L. E., \& Leitenberg, H. (2001). The impact of child sexual abuse and stigma on methods of coping with sexual assault among undergraduate women. Child Abuse \& Neglect, 25(10), 1343-1361. doi: 10.1016/s0145-2134(01)00279-4

Held, P., Owens, G.P., Schumm, J.A., Chard, K.M., \& Hansel, J.E. (2011). Disengagement coping as a mediator between trauma-related guilt and PTSD severity. Journal of Traumatic Stress, 24(6), 708-715. doi: 10.1002/ana.23595

Hendin, H., \& Haas, A. (1991). Suicide and guilt as manifestations of PTSD in Vietnam combat veterans. American Journal of Psychiatry, 148(5), 586-591.

Henning, K. R., \& Frueh, B. C. (1997). Combat guilt and its relationship to PTSD symptoms. Journal Of Clinical Psychology, 53(8), 801-808. 
Institute of Medicine. (2006). Posttraumatic stress disorder: Diagnosis and assessment. Washington D.C.: The National Academies Press.

Jakupcak, M., Conybeare, D., Phelps, L., Hunt, S., Holmes, H. A., Felker, B., Klevens, M., \& McFall, M. E. (2007). Anger, hostility, and aggression among Iraq and Afghanistan war veterans reporting PTSD and subthreshold PTSD. Journal of Traumatic Stress, 20(6), 945-954. doi: 10.1002/jts.20258

Jakupcak, M., \& Tull, M. T. (2005). Effects of trauma exposure on anger, aggression, and violence in a nonclinical sample of men. Violence And Victims, 20(5), 589-598.

Jaycox, L. H., Foa, E. B., \& Morral, A. R. (1998). Influence of emotional engagement and habituation on exposure therapy for PTSD. Journal of Consulting and Clinical Psychology, 66(1), 185-192. doi: 10.1037//0022-006x.66.1.185

Kamarck, T.W., Manuck, S.B., \& Jennings, J.R. (1990). Social support reduces cardiovascular reactivity to psychological challenge: A laboratory model. Psychosomatic Medicine, 52, 42-58.

Kaplan, D. M., Smith, T., \& Coons, J. (1995). A validity of the subjective units of discomfort (SUD) score. Measurement and Evaluation in Counseling and Development, 27, 195-199.

Kazdin, A. E., \& Wilcoxin, L. A. (1976). Systematic desensitization and nonspecific treatment effects: A methodological evaluation. Psychological Bulletin, 83, 729758.

Keane, T. M., \& Kaloupek, D. G. (1997). Comorbid psychiatric disorders in PTSD. Annals of the New York Academy of Sciences, 821(1), 24-34. doi: 10.1111/j.17496632.1997.tb48266.x 
Kessler, R. C., Sonnega, A., Bromet, E., Hughes, M., \& Nelson, C. B. (1995).

Posttraumatic stress disorder in the national comorbidity survey. Archives of General Psychiatry, 52(12), 1048-1060. doi:

10.1001/archpsyc.1995.03950240066012

Krantz, D. S., Olson, M. B., Francis, J. L., Phankao, C., Merz, C. N. B., Sopko, G., Vido, D.A., Shaw, L.J., Sheps, D.S., Pepine, C.J., \& Matthews, K. A. (2006). Anger, Hostility, and Cardiac Symptoms in Women with Suspected Coronary Artery Disease: The Women's Ischemia Syndrome Evaluation (WISE) Study. Journal of Women's Health, 15(10), 1214-1223. doi:10.1089/jwh.2006.15.1214

Kubany, E., Abueg, F., Owens, J., Brennan, J., Kaplan, A., \& Watson, S. (1995). Initial examination of a multidimensional model of trauma-related guilt: Applications to combat veterans and battered women. Journal of Psychopathology and Behavioral Assessment, 17(4), 353-376. doi:10.1007/bf02229056

Kubany, E. S., Haynes, S. N., Abueg, F. R., Manke, F. P., Brennan, J. M., \& Stahura, C. (1996). Development and validation of the Trauma-Related Guilt Inventory (TRGI). Psychological Assessment, 8(4), 428-444. doi:10.1037/10403590.8 .4 .428

Kubany, E. S., \& Watson, S. B. (2003). Guilt: Elaboration of a multidimensinoal model. Psychological Record, 53(1), 51-100.

Lang, P. J., Davis, M., Ouml, \& hman, A. (2000). Fear and anxiety: animal models and human cognitive psychophysiology. Journal of Affective Disorders, 61(3), 137159. 
Marx, B. P., Foley, K. M., Feinstein, B. A., Wolf, E. J., Kaloupek, D. G., \& Keane, T. M. (2010). Combat-related guilt mediates the relations between exposure to combatrelated abusive violence and psychiatric diagnoses. Depression \& Anxiety (10914269), 27(3), 287-293. doi: 10.1002/da.20659

Mayou, R. A., Ehlers, A., \& Bryant, B. (2002). Posttraumatic stress disorder after motor vehicle accidents: 3-year follow-up of a prospective longitudinal study. Behaviour Research and Therapy, 40(6), 665-675.

McHugh, T., Forbes, D., Bates, G., Hopwood, M., \& Creamer, M. (2011). Anger in PTSD: Is there a need for a concept of PTSD-related posttraumatic anger? Clinical Psychology Review, 32, 93-104. doi: 10.1016/j.cpr.2011.07.013

Meffert, S. M., Metzler, T. J., Henn-Haase, C., McCaslin, S., Inslicht, S., Chemtob, C., Neylan, T., \& Marmar, C. R. (2008). A prospective study of trait anger and PTSD symptoms in police. Journal of Traumatic Stress, 21(4), 410-416. doi: $10.1002 /$ jts. 20350

Michael, T., Halligan, S. L., Clark, D. M., \& Ehlers, A. (2007). Rumination in posttraumatic stress disorder. Depression and Anxiety, 24, 307-317. doi: 10.1002/da.20228

Monson, C. M. \& Friedman, M.J. (2006). Back to the future of understanding trauma. Cognitive-Behavioral Therapies for Trauma. V. M. Follette and J. I. Ruzek (Eds). New York, NY, The Guilford Press: 1-13.

Nishith, P., Nixon, R.D.V., \& Resick, P.A. (2005). Resolution of trauma-related guilt following treatment of PTSD in female rape victims: A result of cognitive processing therapy 
targeting comorbid depression? Journal of Affective Disorders, 86, 259-265. doi:10.1016/j.jad.2005.02.013

Nolen-Hoeksema, S. (1991). Responses to depression and their effects on the duration of depressive episodes. Journal of Abnormal Psychology, 100, 569-582. doi:10.1037/0021-843X.100.4.569

Nolen-Hoeksema, S. (2000). The role of rumination in depressive disorders and mixed anxiety/depressive symptoms. Journal of Abnormal Psychology, 109, 504-511. doi:10.1037//0021-843X.109.3.504

Novaco, R. W., \& Chemtob, C. M. (2002). Anger and combat-related posttraumatic stress disorder. Journal of Traumatic Stress, 15(2), 123-132.

Olatunji, B. O., Ciesielski, B. G., \& Tolin, D. F. (2010). Fear and loathing: A metaanalytic review of the specificity of anger in PTSD. Behavior Therapy, 41(1), 93105. doi:10.1016/j.beth.2009.01.004

Opp, R. E., \& Samson, A. Y. (1989). Taxonomy of guilt for combat veterans. Professional Psychology: Research and Practice, 20(3), 159-165. doi:10.1037//0735-7028.20.3.159

Orth, U., \& Wieland, E. (2006). Anger, hostility, and posttraumatic stress disorder in trauma-exposed adults. Journal of Consulting and Clinical Psychology, 74(4), 698-706. doi:10.1037/0022-006X.74.4.698

Ouimette, P., Cronkite, R., Prins, A., \& Moos, R. H. (2004). Posttraumatic stress disorder, anger and hostility, and physical health status. The Journal of Nervous and Mental Disease, 192(8), 563-566. 
Owens, G. P., Chard, K. M., \& Cox, T. A. (2008). The relationship between maladaptive cognitions, anger expression, and posttraumatic stress disorder among veterans in residential treatment. Journal of Aggression, Maltreatment \& Trauma, 17(4), 439452. doi:10.1080/10926770802473908

Owens, G. P., Steger, M. F., Whitesell, A. A., \& Herrera, C. J. (2009). Posttraumatic stress disorder, guilt, depression, and meaning in life among military veterans. Journal of Traumatic Stress, 22(6), 654-657. doi:10.1002/jts.20460

Paunovic, N. (1998). Cognitive factors in the maintenance of PTSD. Scandinavian Journal of Behaviour Therapy, 27(4), 167-178.

Pitman, R.K., Altman, B., Greenwald, E., Longpre, R.E.,Macklin, M.L., Poire, R.E., \& Steketee, G.S. (1991). Psychiatric complications during flooding therapy for posttraumatic stress disorder. Journal of Clinical Psychiatry, 52, 17-20.

Post, L. M., Zoellner, L. A., Youngstrom, E., \& Feeny, N. C. (2011). Understanding the relationship between co-occurring PTSD and MDD: Symptom severity and affect. Journal of Anxiety Disorders, 25, 1123-1130. doi:10.1016/j.janxdis.2011.08.003

Preacher, K.J., \& Hayes, A.F. (2004). SPSS and SAS procedures for estimating indirect effects in simple mediation models. Behavior Research Methods, Instruments, and Computers, 36, 717-731.

Preacher, K.J., \& Hayes, A.F. (2008). Asymptotic and resampling strategies for assessing and comparing indirect effects in multiple mediation models. Behavior Research Methods, 40, 879-891. doi:10.3758/BRM.40.3.879

Pyne, J.M., Rost, K.M., Farahati, F., et al. (2005). One size fits some: the impact of patient treatment attitudes on the cost effectiveness of a depression primary care 
intervention. Psychological Medicine, 35, 839-854.

doi:10.1017/S0033291704003332

Resick, P. A., Nishith, P., Weaver, T. L., Astin, M. C., \& Feuer, C. A. (2002). A comparison of cognitive-processing therapy with prolonged exposure and a waiting condition for the treatment of chronic posttraumatic stress disorder in female rape victims. Journal of Consulting and Clinical Psychology, 70(4), 867879. doi:10.1037//0022-006x.70.4.867

Resnick, H. S., Kilpatrick, D. G., Dansky, B. S., Saunders, B. E., \& Best, C. L. (1993). Prevalence of civilian trauma and posttraumatic stress disorder in a representative national sample of women. Journal of Consulting and Clinical Psychology, 61(6), 984-991. doi:10.1037/0022-006x.61.6.984

Riggs, D. S., Dancu, C. V., Gershuny, B. S., Greenberg, D., \& Foa, E. B. (1992). Anger and post-traumatic stress disorder in female crime victims. Journal of Traumatic Stress, 5(4), 613-625.

Rizvi, S. L., Vogt, D. S., \& Resick, P. A. (2009). Cognitive and affective predictors of treatment outcome in cognitive processing therapy and prolonged exposure for posttraumatic stress disorder. Behaviour Research and Therapy, 47(9), 737-743. doi:10.1016/j.brat.2009.06.003

Rosen, C. S., Murphy, R. T., Chow, H. C., Drescher, K. D., Ramirez, G., Ruddy, R., \& Gusman, F. (2001). Posttraumatic stress disorder patients' readiness to change alcohol and anger problems. Psychotherapy: Theory, Research, Practice, Training, 38(2), 233-244. doi:10.1037/0033-3204.38.2.233 
Rothbaum, B. O., Foa, E. B., Riggs, D. S., Murdock, T., \& Walsh, W. (1992). A prospective examination of post-traumatic stress disorder in rape victims. Journal of Traumatic Stress, 5(3), 455-475.

Seidler, G. H. (1997). From object-relations theory to the theory of alterity: shame as an intermediary between the interpersonal world and the inner world of psychic structure. American Journal of Psychotherapy, 51(3), 343-356.

Simms, L.J., Watson, D., \& Doebbling, B.N. (2002). Confirmatory factor analyses of postraumatic stress symptoms in deployed and nondeployed veterans of the gulf war. Journal of Abnormal Psychology, 111(4), 636-647. doi:10.1037//0021843X.111.4.637

Sobel, M.E. (1982). Asymptotic confidence intervals for indirect effects in structural equation models. Sociological Methodology, 13, 290-312.

Spielberger, C. D. (1988). Manual for the State Trait Anger Expression Inventory, STAXI. Odessa, FL: PAR.

Spielberger, C. D., E. H. Johnson, et al. (1985). The experience and expression of anger: Construction and validation of an anger expression scale. Anger and hostility in cardiovascular and behavioral disorders. M. A. Chesney and R. H. Rosenman (eds). Washington D.C., Hemisphere: 5-30.

Stapleton, J. A., Taylor, S., \& Asmundson, G. J. G. (2006). Effects of three PTSD treatments on anger and guilt: Exposure therapy, eye movement desensitization and reprocessing, and relaxation training. Journal of Traumatic Stress, 19(1), 1928. doi: 10.1002/jts.20095 
Street, A. E., Gibson, L. E., \& Holohan, D. R. (2005). Impact of childhood traumatic events, trauma-related guilt, and avoidant coping strategies on PTSD symptoms in female survivors of domestic violence. Journal of Traumatic Stress, 18(3), 245252. doi: $10.1002 /$ jts. 20026

Swan, S. C., Gambone, L. J., Fields, A. M., Sullivan, T. P., \& Snow, D. L. (2005).

Women who use violence in intimate relationships: the role of anger, victimization, and symptoms of posttraumatic stress and depression. Violence And Victims, 20(3), 267-285.

Tangney, J.P., \& Dearing, R.L. (2002). Shame and Guilt. New York, NY: The Guilford Press.

Tangney, J. P., Wagner, P., Fletcher, C., \& Gramzow, R. (1992). Shamed into Anger? The relation of shame and guilt to anger and self-reported aggression. Journal of Personality and Social Psychology, 4, 669-675. doi:10.1037/0022-3514.62.4.669

Tangney, J., Wagner, P. E, Hill-Barlow, D., Marschall, D. E., \& Gramzow, R. (1996). Relation of shame and guilt to constructive versus destructive responses to anger across the lifespan. Journal of Personality and Social Psychology, 70, 797-809. doi: $10.1037 / 0022-3514.70 .4 .797$

Tarrier, N., Pilgrim, H., Sommerfield, C., Faragher, B., Reynolds, M., Graham, E., \& Barrowclough, C. (1999). A randomized trial of cognitive therapy and imaginal exposure in the treatment of chronic posttraumatic stress disorder. Journal of Consulting and Clinical Psychology, 67, 13-18. doi:10.1037//0022-006x.67.1.13

Taylor, S., Fedoroff, I. C., Koch, W. J., Thordarson, D. S., Fecteau, G., \& Nicki, R. M. (2001). Posttraumatic stress disorder arising after road traffic collisions. Journal 
of Consulting and Clinical Psychology, 69(3), 541-551. doi: 10.1037//0022006X.69.3.541

Taylor, S., Thordarson, D. S., Maxfield, L., Fedoroff, I. C., Lovell, K., \& Ogrodniczuk, J. (2003). Comparative efficacy, speed, and adverse effects of three PTSD treatments: Exposure therapy, EMDR, and relaxation training. Journal of Consulting and Clinical Psychology, 71(2), 330-338. doi: 10.1037/0022006X.71.2.330

Thayer, B. A., Papsdorf, J. D., Davis, R., \& Vallecorsa, S. (1984). Automatic correlates of the subjective anxiety scale. Journal of Behavior Therapy and Experimental Psychiatry, 15, 3-7.

van Minnen, A., Arntz, A., \& Keijsers, G. P. J. (2002). Prolonged exposure in patients with chronic PTSD: predictors of treatment outcome and dropout. Behaviour Research and Therapy, 40(4), 439-457. doi:10.1016/s0005-7967(01)00024-9

van Minnen, A., \& Foa, E.B. (2006). The effects of imaginal exposure length on outcome of treatment for PTSD. Journal of Traumatic Stress, 19(4), 427-438. doi:10.1002/jts.20146

Weiner, B., Graham, S., \& Chandler, C. (1982). Pity, anger, and guilt: An attributional analysis. Personality and Social Psychology Bulletin, 8(2), 226-232. doi:10.1177/0146167282082007

Whiting, D., \& Bryant, R. A. (2007). Role of appraisals in expressed anger after trauma. Clinical Psychologist, 11(1), 33-36. doi:10.1080/13284200601178136 Wilson, J. P., Droždek, B., \& Turkovic, S. (2006). Posttraumatic Shame and Guilt. Trauma, Violence, \& Abuse, 7(2), 122-141. doi:10.1177/1524838005285914 
Wolpe, J., \& Lazarus, A. A. (1966). Behavior therapy techniques. New York: Pergamon Press. 